\title{
Review Article \\ High Density Lipoprotein: Assembly, Structure, Cargo, and Functions
}

\author{
Andrew J. Murphy \\ Haematopoiesis and Leukocyte Biology, Baker IDI Heart and Diabetes Institute, 75 Commercial Road, \\ Melbourne, VIC 3000, Australia \\ Correspondence should be addressed to Andrew J. Murphy; andrew.murphy@bakeridi.edu.au
}

Received 21 October 2013; Accepted 28 November 2013

Academic Editors: X.-P. Chu, G. Cui, F. Moccia, and S. Trapp

Copyright (C) 2013 Andrew J. Murphy. This is an open access article distributed under the Creative Commons Attribution License, which permits unrestricted use, distribution, and reproduction in any medium, provided the original work is properly cited.

Cardiovascular disease (CVD) is the leading cause of death globally. For close to four decades, we have known that high density lipoprotein (HDL) levels are inversely correlated with the risk of CVD. HDL is a complex particle that consists of proteins, phospholipids, and cholesterol and has the ability to carry micro-RNAs. HDL is constantly undergoing remodelling throughout its life-span and carries out many functions. This review summarizes many of the different aspects of HDL from its assembly, the receptors it interacts with, along with the functions it performs and how it can be altered in disease. While HDL is a key cholesterol efflux particle, this review highlights the many other important functions of HDL in the innate immune system and details the potential therapeutic uses of HDL outside of CVD.

\section{Introduction}

Cardiovascular disease (CVD) remains the dominant cause of death globally [1], and while it is recognized as a multifactorial disease with many risk factors, atherosclerosis is responsible for the major pathology contributing to end stage heart disease [2]. Dyslipidemia, or the imbalance of plasma lipid levels, together with disturbances of intracellular lipid metabolism, underlie atherosclerotic plaque development. Such dyslipidemias include increases in both plasma total and low density lipoprotein (LDL) cholesterol leading to LDL modification and increased accumulation of modified LDL in the intima of the vasculature. Alternatively and perhaps more strikingly is the highly robust inverse correlation between high density lipoprotein (HDL) levels and the risk of CVD, independent of plasma LDL levels [3]. We have now come to understand that for every $5 \mathrm{mg} / \mathrm{dL}$ decease in HDL levels below the average $(\sim 50 \mathrm{mg} / \mathrm{dL})$, there is an approximate $25 \%$ increase in the risk of myocardial infarction [3]. However, while plasma HDL levels offer prognostic value, the genetics behind differing HDL levels have failed to show association between increased HDL levels and protection from myocardial infarction [4]. Given the complex interactions of HDL genetics, function, and interplay with
CVD, understanding how HDL modulates cholesterol flux is of increasing significance. Perhaps the most seminal finding of recent times relating to this is the work from Dr. Rader's laboratory which clearly showed that HDL function (i.e., the ability to promote cholesterol efflux from a standardized cell model) was impaired from patients with CVD and was a leading predictor of risk [5]. Thus, it is imperative that HDL composition and function in normal and disease states is comprehensively understood.

\section{Atherosclerosis and Lipids: A Brief Overview}

Atherosclerosis is a complex, progressive disease predominantly occurring in the large arteries of the body. Early research suggested that lipids were a major contributing factor to the onset and progression of the atherosclerotic plaque. This was largely attributed to the strong correlation between hypercholesterolemia and atherosclerosis, along with the dominant role LDL appeared to play $[6,7]$. It was also discovered that controlling lipid levels, in particular lowering LDL through both diet and drug management, had positive effects on reducing the size of the atheroma [8]. However, the pathogenesis of atherosclerosis is complex with many 
other critical processes that contribute to its development and progression. It is generally accepted that inflammation drives plaque progression [9], evident by the secretion of proteases, cytokines, chemokines, soluble adhesion molecules, and reactive oxygen species (ROS) from a dysfunctional endothelium [10].

Increasing the levels and improving the function of HDL are attractive targets to alleviate CVD as HDL possesses a vast array of antiatherosclerotic effects. This is largely due to HDL functioning as a cholesterol acceptor, where HDL promotes cholesterol efflux from lipid-laden macrophages and takes this cholesterol back to the liver for processing. HDL also decreases the activation of leukocytes, platelets, and endothelial cells, functions as an antioxidant, and the recent discovery in regulating haematopoiesis (discussed in detail below). Unfortunately, a number of clinical evaluations of HDL raising therapies have been halted due to either off-target effects or futility, but by no means have these trials disproven the HDL hypothesis. Certainly there is still much interest and hope for HDL targeted therapies to treat people with not only CVD but other inflammatory diseases and some myeloid leukaemias. This review discusses the formation and functions of HDL and how HDL is altered in disease states.

\section{High Density Lipoprotein}

3.1. Overview of HDL Formation. High Density Lipoprotein is a complex particle in terms of size, structure, and the molecules that are associated with HDL. The complexity lies in that these forementioned parameters constantly change throughout the life of the HDL molecule. Apolipoprotein A-I (apoA-I) is the main protein of HDL. ApoA-I accepts lipid to form what is known as pre- $\beta$ HDL, an immature form of HDL. This form of HDL matures by interacting with enzymes, transfer factors, and cellular receptors. Indeed, the "lifecycle" of HDL is quite complex and many interactions between HDL and the surrounding environments are actively investigated. It appears that HDL plays a number of distinct and important roles throughout its maturation from a single apoA-I molecule to the mature HDL molecule; this includes not only cholesterol efflux but also important roles in innate immunity [11-14].

3.2. Structure/Composition. Circulating HDLs are quite diverse and are therefore separated into a number of subpopulations based on shape, size, density, electrophoretic mobility, and apolipoprotein composition (summarised in Figure 1). The assembly of HDL begins with lipidation of apoA-I. Once apoA-I begins to accept lipid, it forms a discoidal shape termed discoidal HDL or pre- $\beta$ HDL [15]. This particle is only transient and when lecithin: cholesterol acyltransferase (LCAT) interacts with pre- $\beta$ HDL it begins to form a spherical shape which it retains [16]. There are two major subfractions of $\mathrm{HDL}$; $\mathrm{HDL}_{2}$ with a density range of 1.063 to $1.125 \mathrm{~g} / \mathrm{mL}$ and $\mathrm{HDL}_{3}$ with a density range of 1.125 to $1.21 \mathrm{~g} / \mathrm{mL}$. These are further separated into five subpopulations based on size: $\mathrm{HDL}_{2 \mathrm{~b}}(10.6 \mathrm{~nm}), \mathrm{HDL}_{2 \mathrm{a}}$
$(9.2 \mathrm{~nm}), \mathrm{HDL}_{3 \mathrm{a}}(8.4 \mathrm{~nm}), \mathrm{HDL}_{3 \mathrm{~b}}(8.0 \mathrm{~nm})$, and $\mathrm{HDL}_{3 \mathrm{c}}$ $(7.6 \mathrm{~nm})[17,18]$. Along with size and density, HDLs also vary in surface charge. Separation by agarose gel electrophoresis reveals alpha, prebeta, or gamma migrating particles $[19,20]$. The alpha migrating particles are generally the spherical HDLs $\left(\mathrm{HDL}_{2}\right.$ and $\left.\mathrm{HDL}_{3}\right)$, the pre- $\beta \mathrm{HDL}$ are lipid poor or discoidal HDL particles, while gamma-HDLs are apoE rich $[19,20]$. HDL can also be classified into 2 major classes based on the apolipoprotein composition; one population has apoA-I only and no apoA-II, while the second population contains both apoA-I and apoA-II. ApoA-I is most likely to be equally divided between all HDLs while apoA-II is virtually only a resident of apoA-I/apoA-II HDL [21-24].

3.3. Apolipoprotein A-I. ApoA-I is a $28 \mathrm{kDa}$ protein synthesized in the liver and intestine where it is released in a lipid free state $[25,26]$. It is comprised of an $\mathrm{N}$-terminal four-helix bundle and two C-terminal helices, essentially formed by the 22-mer repeats [25]. The amphipathic $\alpha$ helices allow for the interaction of the hydrophobic face with phospholipids, while the hydrophilic face of the helices interacts with the aqueous phase [27]. Extensive research into the structure of apoA-I has been conducted over the past few decades where initial algorithms predicted apoA-I to contain as many as $8-9$ helices $[28,29]$. These predictions were confirmed through the use of circular dichroism and infrared spectroscopy [30-32], but has since been disproven with the deduction of the crystal structure of lipid-free apoAI [25]. This revealed that the structure of lipid-free apoA-I contains two helical domains, a four-helix antiparallel bundle formed by the N-terminal three-quarters and a two-helix bundle at the C-terminal quarter of the protein. The crystal structure confirmed the previous hypothesis that the role of the N-terminus of apoA-I is to stabilise lipid-free apoAI $[25,33,34]$. However, even though the crystal structure is available, the field is still challenged as to how apoA-I forms structures with phospholipids (PL) and how it interacts with its receptors. Over the decades, there have been three basic models of the structures that apoA-I/PL discs form, the models are based on two apoA-I molecules surrounding a phospholipid core and can be described as a picket fence, belt, and hairpin [15]. It is now becoming more apparent that the structure of the apoA-I/PL complex is forever changing to form spherical HDL $[15,16,25,35]$. The most recent consensus has arisen from some elegant studies conducted by Sean Davidson's group showing that apoA-I molecules in plasma HDL adopt a "cage-like structure" and the size of the HDL particle is determined by the twisting compaction of these apoA-I molecules [36]. This new understanding of HDL particle formation will provide new insights into how HDL interacts with other lipoproteins and how some of the apoA-I mimetic peptides can incorporate into HDL particles.

3.4. ApoA-I Variants. There are a number of naturally occurring variants of apoA-I. Four of the most well defined are apoA- $\mathrm{I}_{\text {Milano }}$, apoA- $\mathrm{I}_{\text {Paris }}$, apoA- $\mathrm{I}_{\text {Pisa }}$, and apoA- $\mathrm{I}_{\text {Finland }}$ $\left(\right.$ apoA-I $\mathrm{IIN}_{\mathrm{FN}}$ [37-40]. Both apoA-I $\mathrm{I}_{\text {Milano }}$ and apoA-I $\mathrm{I}_{\text {Paris }}$ have an arginine residue mutated to a cysteine, the substitution 


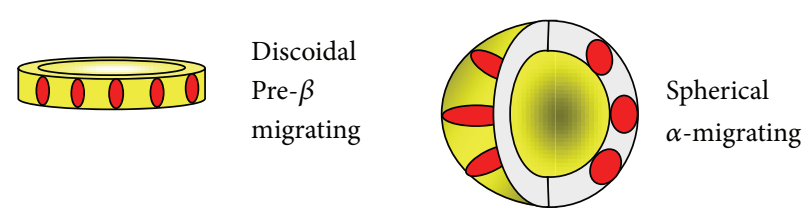

(a) Particle shape

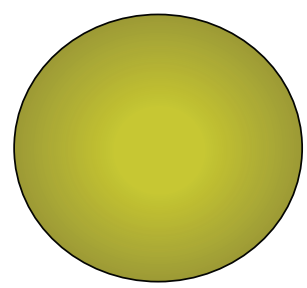

$\mathrm{HDL}_{2 \mathrm{~b}}(10.6 \mathrm{~nm})$

$\mathrm{HDL}_{2 \mathrm{a}}(9.2 \mathrm{~nm})$

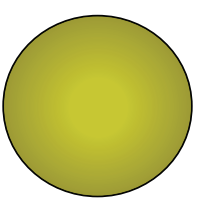

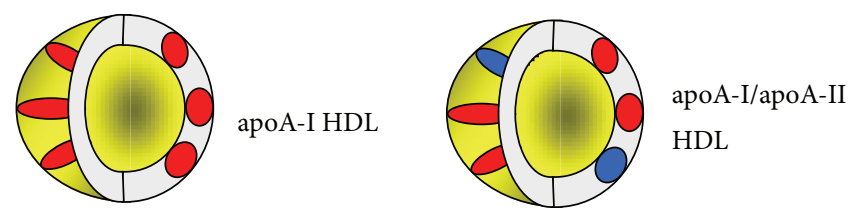

(b) Apolipoprotein composition

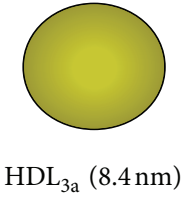

$\mathrm{HDL}_{3 \mathrm{~b}}(8.0 \mathrm{~nm})$
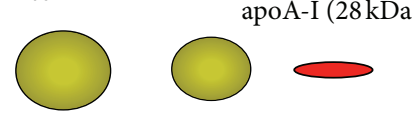

$\mathrm{HDL}_{3 \mathrm{c}}(7.6 \mathrm{~nm})$

(c) Particle size

FIGURE 1: HDL subpopulations characterised by size, shape, and apolipoproteins. (a) The two shapes of HDL and their migratory characteristics (red = apoA-I). (b) HDL can contain apoA-I (red) or both apoA-I and apoA-II (blue). (c) The various particle sizes of HDL, from lipid-free apoA-I through to the larger more mature $\mathrm{HDL}_{2 \mathrm{~b}}$.

in apoA- $\mathrm{I}_{\text {Milano }}$ occurs at residue 173 while in apoA- $\mathrm{I}_{\text {Paris }}$ this occurs at residue $151[39,40]$. The cysteine is unique to these variants as wild-type apoA-I does not contain any cysteines. However, homodimers of these variants form disulfide bonds, but this appears to have no effect on the ability to bind dimyristoylphosphatidylcholine (DMPC) or promote cholesterol efflux [41-43]. Although both mutations in heterozygous individuals result in decreased levels of circulating HDL, studies demonstrate the carriers are at a decreased risk of developing atherosclerosis [39, 40, 43]. Subsequently, an important study by Nissen and coworkers demonstrated the effectiveness of apoA- $\mathrm{I}_{\text {Milano }} / \mathrm{PL}$ infusions on reducing atheroma volume in patients suffering from coronary atherosclerosis [44]. While apoA- $\mathrm{I}_{\text {Milano }}$ is suggested to have superior antiatherosclerotic abilities over native apoA-I, very few studies have compared these apoA-I molecules head-to-head. Alexander et al. compared human native apoA-I to apoA-I $\mathrm{I}_{\text {Milano }}$ by expressing these proteins in Apoa- $1^{-/-}$mice using an adeno-associated virus. They found no difference in the cholesterol efflux abilities from macrophages between the native apoA-I and apoA- $\mathrm{I}_{\text {Milano }}$ suggesting that the proposed superior antiatherosclerotic effects of apoA- $\mathrm{I}_{\text {Milano }}$ were unlikely to be mediated by enhanced macrophage cholesterol efflux [45]. Both apoA- $\mathrm{I}_{\text {Pisa }}$ and apoA-I $\mathrm{I}_{\mathrm{FIN}}$ have a leucine to arginine substitution at residue 141 and 159, respectively [37-40]. This results in hypoalphalipoproteinemia and is due to the inability of these apoA-I variants to interact with LCAT [37, 46, 47]. Coronary artery disease has been correlated with these mutations but is not always observed [48].

3.5. HDL Remodelling/Interacting Proteins. There are a number of proteins/enzymes that are found on HDL and participate in remodelling HDL as it progresses from lipid-free apoA-I to mature HDL. These include the following.
3.5.1. Lecithin: Cholesterol Acyltransferase. LCAT is synthesised in the liver and secreted into the circulatory system [49]. LCAT interacts with unesterified cholesterol in discoidal or pre- $\beta$ HDL to generate cholesterol esters (CE), which move to the core of HDL causing it to undergo a conformational change from a discoidal shape to a sphere $[50,51]$. However, LCAT requires activation by apoA-I before it can esterify cholesterol [50]. Natural mutations in apoA-I can inhibit LCAT binding and activation to result in low plasma HDL, this is also observed in people with various mutations in LCAT leading to LCAT deficiency or fish eye disease [52].

3.5.2. Cholesterol Ester Transfer Protein. Cholesterol Ester Transfer Protein (CETP) is expressed in the liver and transfers CEs between lipoproteins [53]. There has been much debate on the role of CETP as a proatherogenic or antiatherogenic molecule [54-56]. As CETP has the ability to transfer CE from HDL to other lipoproteins such as HDL, it can remodel spherical HDL, which reduces the size of HDL and can cause the dissociation of lipid-free apoA-I $[57,58]$. However patients with CETP deficiency have high levels of HDL and a lower prevalence of coronary heart disease making this an attractive drug target [56]. This data has effectively given rise to the development of CETP inhibitors (CEPTi). Unfortunately, some CEPTis have already failed in clinical trials due to off-target effects on blood pressure [59], or due to futility [60] with the less potent CETPi dalcetrapib. However, there is still hope as the safety data from anacetrapib trial revealed it has potent HDL raising effects while also lowering LDL cholesterol, and although it was not designed to test outcomes, the investigators made the encouraging observation that there was less revascularizations in the active group compared to placebo [61].

3.5.3. Paraoxonase-1. A member of the paraoxonase (PON) family PON-1 is synthesised in the liver where a portion 
is secreted into the plasma and is found at varying concentrations [62]. PON-1 can bind and circulate with HDL giving antioxidant properties to HDL [63]. While the precise mechanism for PON-1 binding to HDL is not completely understood, it is suggested that HDL mediates the release of PON-1 from the plasma membranes of cells as incubation of PON-1 transfected cells with HDL caused a significant increase in the media activity of the enzyme and a decrease in cell-surface activity compared to PON-1 cells alone [64]. Another area of conjecture is the type of HDL that associates with PON-1. Studies using an immunoabsorption method with an anti-PON-1 antibody demonstrated that only some HDLs from total plasma HDL were associated with PON-1, indicating that a certain species of HDL interacts with PON1 [65]. However, there are conflicting reports on the species of HDL that PON-1 is associated with, PON-1 is suggested to interact with the smaller denser $\mathrm{HDL}_{3}$ [66-69], while other reports suggest $\mathrm{PON}-1$ interacts with the larger less dense $\mathrm{HDL}_{2}[65,70]$. In any case, PON-1 plays an important role in the anti-inflammatory properties of HDL, where it functions as an antioxidant, preventing the oxidation of atherogenic lipoproteins such as LDL.

\subsection{HDL Cargo}

3.6.1. Proteomics. While apoA-I is the major protein by far, comprising of approximately $70 \%$ of all protein found in HDL $[23,24]$, there are a number of other proteins that are associated with HDL. ApoA-II is the second most abundant protein at approximately $10-20 \%$ while other apolipoproteins (A-IV, CI-IV, D, E, F, H, and M) are also found [21-24]. However, it is important to note that these molecules are not always associated with HDL and are dependent on the environment and the remodelling stage of which HDL is at [22-24].

Pioneering studies from the Heinecke laboratory have shown that HDL is an extremely dynamic molecule and carries a cargo of proteins [22]. Thus, another modification of HDL in disease is the proteome of HDL. Viasir and coworkers through a series of elegant mass-spectrometry analysis discovered that HDL carries a vast array of proteins involved in lipid metabolism, proteinase inhibition, complement activation, and the acute phase response [22]. HDL isolated from patients with established coronary artery disease (CAD) had a distinct HDL proteome signature. Proteins involved in lipid metabolism: apoE, apoC-IV, and apoA-IV; oxidative stress: paraoxonase-1; and the immune system: complement factor $\mathrm{C} 3$, were enriched in CAD patients compared to healthy controls. Vitronectin, haptoglobin-related protein, and clusterin appeared to be enriched in control subjects but this failed to reach statistical significance. A subsequent study where HDL was isolated from newly diagnosed CAD patients prior to and 1 year after combination therapy of niacin and atorvastatin revealed that the HDL proteome is remodeled after intervention. After CAD patients had been treated with lipid modulating drugs for 1 year, their HDL became enriched in apoF and phospholipid transfer protein while the levels of apoE were reduced. There was also a trend for increased apoJ and decreased apoC-II. The functional significance of these findings warrants further research, and to date it is not fully understood. Whether enrichment of certain proteins in HDL from CAD is causative or detrimental to its function, or an adaptation to compensate for disease will be interesting to decipher.

3.6.2. Micro-RNAs. Recently, HDL has been shown to carry micro-RNAs (miRNAs), which are short noncoding regulatory RNAs that modulate biological processes by controlling gene expression through mRNA targeting and translational repression [71]. The miRNA signature in $\mathrm{HDL}$ particles was compared between healthy controls and subjects with familial hypercholesterolemia $(\mathrm{FH})$. This revealed a distinct miRNA profile between the two groups. HDL from subjects with $\mathrm{FH}$ had an overall increase in the amount of miRNAs compared to controls. Additionally, volcano plots revealed that 22 miRNAs were significantly different between $\mathrm{FH}$ and controls and this did not include miRNAs that were completely unique (present or absent). The most abundant miRNA in normal subjects was mir-135a, mir-188-5p, and mir-877 and in subjects with FH, it was mir-223, mir-105, and mir-106a. These findings were confirmed using a mouse model of $\mathrm{FH}$, the $\mathrm{Ldlr}^{-/-}$mouse, which showed similar miRNa profiles as observed in the human subjects. It was also shown that the infusion of reconstituted HDL (rHDL) (free of miRNAs) into WT, Apoe $e^{-/-}$on chow or Apoe $e^{-/-}$on a high fat, high cholesterol (WTD) became loaded with miRNAs in vivo. HDL-miRNAs from WTD-fed $A p o e^{-/-}$were distinctly different from chow-fed $A p o e^{-/-}$or WT mice suggesting that the miRNA signatures were altered in atherosclerotic mice. It was also suggested that cellular transporters of cholesterol, such as ABCA1, can facilitate the loading of rHDL with miRNAs and thus could reflect the events occurring within the cell.

It was shown that HDL not only carries endogenous miRNAs, but can also deliver these to cells resulting in functional gene regulatory consequences. The delivery of miRNAs from HDL to hepatocytes was mediated in an scavenger receptor class B member 1 (SR-BI) dependent fashion [71]. Loading HDL with mir-223 resulted in effective delivery to hepatocytes. The functional outcome was confirmed when a reduction in Ras homologue gene, family member B, and ephrin A1, targets of mir-233 were found to be significantly down regulated.

Thus, the recent advances in HDL biology suggest that there is still much to understand of how this complex particle acts in vivo and how its functions can be hampered in disease. Exactly how these modifications of HDL alter its overall function and the precise links to innate immunity or the relevance to more broader biological pathways remains to be elucidated.

\section{Cholesterol Efflux and the Formation of HDL}

Cholesterol efflux is the first step of reverse cholesterol transport (RCT) and is described as the ability of HDL to 
remove cholesterol from extrahepatic tissues (specifically the vasculature) for clearance in the liver. This event is carried out by HDL through a number of pathways utilising a variety of receptors and HDL particles.

4.1. Apolipoprotein A-I. The formation of pre- $\beta$ HDL: apoA-I becomes lipidated through a receptor-mediated event, where apoA-I interacts with the ATP binding cassette transporter A-1 (ABCA1) $[72,73]$. This reaction gives rise to pre- $\beta$ HDL. The smallest $(\approx 80 \mathrm{kDa})$ of these disc-like structures is thought to consist largely of two apoA-I molecules, PLs and free cholesterol (FC) [74]. However, smaller lipid poor HDL particles have also been suggested to consist of a single apoAI molecules and $\mathrm{PL}$ at $\approx 40 \mathrm{kDa}$ [75]. These are suspected to be formed by spontaneous association between apoA-I and PL [76]. While apoA-I can be lipidated spontaneously, the requirement for ABCA1 to mediate efflux to apoA-I is crucial for the development of HDL as individuals with a nonfunctional ABCA1 (Tangiers Disease) have significantly reduced plasma HDL [77].

4.2. Pre- $\beta H D L$. The formation of $\alpha$-migrating HDL: circulating pre- $\beta$ HDL accounts for approximately $5 \%$ of total HDL in normal healthy plasma. The apoA-I molecules in pre- $\beta$ HDL activate the enzyme LCAT and esterification of the FC occurs [50] resulting in the change of shape of the particle from a disc to a spherical structure. Typically termed $\mathrm{HDL}_{3}$, this form of HDL can further interact with a number of receptors to facilitate cholesterol efflux, interact with other lipoproteins, or bind many other soluble factors. However, it has also been demonstrated that this discoidal HDL can directly interact with another transporter, ATP binding cassette transporter G-1 (ABCG1), to promote cholesterol efflux [78].

4.3. $\alpha$-Migrating HDL. Mature $\alpha$-migrating HDL accounts for the majority of circulating $\mathrm{HDL}$ and includes both $\mathrm{HDL}_{2}$ and $\mathrm{HDL}_{3}$. These HDL molecules are actively involved in the process of RCT. HDL has been shown to bind and facilitate cholesterol efflux from both ABCG1 and scavenger receptorB1 (SR-B1) [79-82]. While SR-B1 interacts with a broad range of HDL particles, it predominantly effluxes to the larger CE rich HDL particles [82]. ABCG1 appears to efflux equally to both pre- $\beta$ and $\alpha$-migrating HDLs [78-80].

\subsection{Receptors Involved in Cholesterol Efflux}

4.4.1. ATP-Binding Cassette Transporter A-1. ABCA1 is a member of the $\mathrm{ABC}$ transporter superfamily which is divided into seven classes [83]. As their name suggests, ABC transporters require ATP to generate the energy to transport metabolites across membranes [83]. The ABC transporters can be divided into two subclasses: (1) whole transporters, comprising of two units similar in structure that are covalently linked and (2) half transporters, and these have a single structural unit and are required for either heteroor homodimers to function. ABCA1 is a full transporter; therefore, it is not required to form dimers to function [84].
Each of the two structures of ABCA1 transverses the plasma membrane six times and includes a nucleotide binding domain, a Walker A and B site (involved in ATP hydrolysis), and a Walker $\mathrm{C}$ domain unique to $\mathrm{ABC}$ transporters [83]. ABCA1 is also predicted to have 2 large extracellular loops that are highly glycosylated and linked by disulfide bonds $[83,85]$. ABCA1 is under the transcriptional regulation of the nuclear receptors liver $\mathrm{X}$ receptor (LXR) and retinoid $\mathrm{X}$ receptor (RXR) and as expected, it is markedly upregulated when cells are overloaded with cholesterol [86-88].

As mentioned earlier, ABCA1 facilitates efflux of cholesterol and PL to lipid-poor apoA-I [72, 73]. Based on the homology of $\mathrm{ABCA} 1$ to other $\mathrm{ABC}$ transporters, there are suggestions that ABCA1 functions with a flippase activity to transfer lipids from the inside of the plasma membrane to the acceptor apoA-I $[72,89]$. There are a number of theories detailing how ABCA1 delivers lipids to apoA-I, two of the most accepted until recently were the exocytosis model and the retroendocytosis model. The exocytosis model proposed that intracellular cholesterol is parcelled into transport vesicles possibly in the Golgi apparatus and these vesicles translocate to the plasma membrane and associate with ABCA1 which then facilitates the removal of cholesterol [90]. The retroendocytosis model suggests that apoA-I first docks with ABCA1 and that this complex is endocytosed in vesicles to intracellular sites of cholesterol where ABCA1 pumps lipids into the vesicle lipidating apoA-I. This complex can then be exocytosed and pre- $\beta$ HDL is released [91-94]. Studies crediting this model have demonstrated the rapid cycling of ABCA1 between late endosomal/lysosomal compartments which contain apoA-I and have shown that in ABCA1 defective cells, these compartments accumulate cholesterol [95, 96]. The dominant model for ABCA1-mediated cholesterol efflux is yet to be confirmed, and may depend on the location of cells effluxing to apoA-I as the retroendocytosis model may be a mechanism for movement of HDL into the intimal region of the vessel $[93,94]$. However, a study by Vedhachalam and co-workers described a three-step process for efflux to apoA-I [97]. Step 1 describes the initial binding of apoA-I to ABCA1 which facilitates the stabilisation of ABCA1 at the plasma membrane, triggering a number of signalling events or posttranslational modifications of apoAI (discussed in detail below). Further, this binding of apoA-I leads to PL translocation through the transporter, ultimately resulting in strain of the membrane due to asymmetrical PL packing, which needs to be relieved. Step 2 involves the plasma membrane protruding to the extracellular space, creating space between PL polar groups, which allows for the amphipathic $\alpha$-helices of apoA-I to enter. Step 3 is the ratelimiting step, involving the solubilisation of the PL bilayer surrounding apoA-I, once this is achieved, discoidal HDL particles are released.

4.4.2. ABCA-1 Posttranslational Modifications. There are a number of intracellular phosphorylation sites in ABCA1 that appear to be largely involved in the stabilisation/degradation of ABCA1. These include the following. 


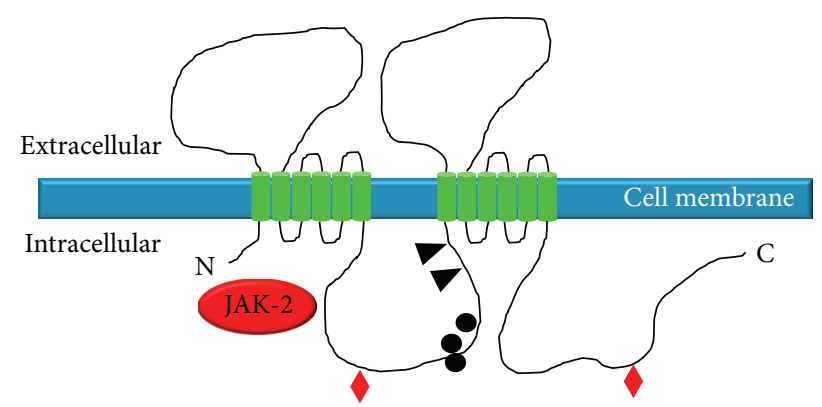

FIGURE 2: ABCA1 cholesterol efflux and stabilising/destabilising modifications. JAK-2 (red) is activated upon apoA-I binding, resulting in autophosphorylation of JAK-2, stabilisation of ABCA1, increased apoA-I binding, and cholesterol efflux. Phosphorylation of the tyrosine residues in the PEST motif (indicated by the black triangles) results in ABCA1 degradation. Protein Kinase A phosphorylates serines (indicated by the red diamonds) required for lipid transport. Protein Kinase CK2 (indicated by the black circles) phosphorylates $\mathrm{ABCA1}$ and down-regulates the transporters activity.

\subsubsection{Destabilisation/Decreased Activity}

PEST Motif. A proline-glutamate-serine-threonine (PEST motif, Figure 2) is located between residues 1283-1306 in the first intracellular loop. Phosphorylation of T1286 and T1305 in the PEST motif facilitates proteolysis by an unknown member of the calpain protease family $[98,99]$.

Protein Kinase CK2. Protein kinase CK2 (PKCK2, Figure 2) is a serine/threonine kinase which phosphorylates ABCA1 at T1242, T1243, and S1255 [100]. Site-directed mutagenesis preventing PKC phosphorylation of ABCA1 lead to an increase in lipid flipping, apoA-I binding to cells, and efflux [100]. This suggests that PKCK2 is a down-regulator of ABCA1 activity.

\subsubsection{Stabilisation/Increased Activity}

Protein Kinase A. Protein kinase A (PKA, Figure 2) phosphorylates serines 1042 and 2054. It has been demonstrated that the activation of PKA by cyclic AMP (cAMP) is required for optimal lipid transport but has no net effect on apoA-I binding to ABCA1 $[101,102]$.

Protein Kinase C. Protein kinase C (PKC) plays a role in ABCA1 stabilisation and there are suggestions that it may also influence the lipid transport activity of ABCA1. Inhibition of $\mathrm{PKC}$ has been demonstrated to decrease cholesterol efflux to both HDL and apoA-I, whereas activation of PKC increases efflux to these acceptors. The latter finding however was described prior to the discovery of ABCA1 [103-106] and warrants confirmation.

Janus Kinase-2. The Janus kinase (JAK, Figure 2) family of tyrosine kinases (JAK-1, JAK-2, JAK-3, and TyK2) are receptor-associated kinases involved in cytoplasmic signal transduction pathways that are initiated when cytokines interact with their respective receptors [107]. This cytokine induced activation of the JAK family results in the recruitment and activation of the signal transducer and activation of transcription (STAT) family. Recently JAK-2 has been demonstrated to play a pivotal role in cholesterol efflux to apoA-I through ABCA1. It has been shown that when JAK2 is inhibited in ABCA1 expressing cells, cholesterol and phospholipid efflux to apoA-I is reduced. Furthermore, the ability of apoA-I to bind to ABCA1 is markedly attenuated. Inhibition of JAK-2 has no effect on either ABCA1 expression (membrane or total) or ABCA1 phosphorylation. Interestingly, cells expressing ABCA1 acutely incubated with apoA-I lead to autophosphorylation of JAK-2. This autophosphorylation is dependent on apoA-I interacting with ABCA1 and occurs rapidly (less than $1 \mathrm{~min}$ ). ABCA1 null cells incubated with apoA-I show no JAK-2 activation. A mutant cell line $(\gamma 2 \mathrm{~A})$ lacking JAK-2 confirmed that JAK-2 is required for cholesterol and phospholipid efflux to apoA-I and apoA-I binding to ABCA1.

4.4.5. ATP-Binding Cassette Transporter A-1. ABCG1 is also a member of the ABC transporters, but unlike ABCA1, $A B C G 1$ is a half transporter and requires homodimerization to function. ABCG1 promotes cholesterol efflux to mature HDL particles and is under the transcriptional control of LXR/RXR [79]. Interestingly, deletion of $A b c g 1$ in mouse models of atherosclerosis generally results in a decrease in lesion size [108-110]. However, some studies have observed increased lesion in mice deficient in Abcgl and this seems to depend on the duration of the study and stage of the atherosclerotic lesion (i.e., developing versus advanced) [111, 112]. It appears that with the longer studies, more macrophage apoptoses occur which likely explain the decreased lesion size [110]. ABCG1 protects macrophages from apoptosis by facilitating the efflux of the toxic oxysterols, which are present in oxidized LDL within the vessel wall [113]. Deletion of Abcg1 along with Abcal also makes macrophages more susceptible to apoptosis during efferocytosis due to increased assembly of the nicotinamide adenine dinucleotide phosphateoxidase (NADPH) oxidase 2 complex, which drives Jnk activation and initiation of cell death pathways [114]. While the atherosclerotic lesions in Abcgl deficient mice are smaller, they do appear to be more inflamed. This is due to $A b c g 1^{-/-}$ macrophages being more responsive to toll like receptor ligands and therefore producing more inflammatory cytokines and enhancing the recruitment of neutrophils [115]. We have also observed that macrophages deficient in Abcg1 and Abcal have significantly impaired migration, suggesting that these cells become trapped in the lesion [116]. We found that cholesterol became trapped on the inner leaflet of the plasma membrane and increased Racl plasma membrane localization and activation. Thus, even though deletion of Abcg1 results in smaller lesions, these lesions are likely to be less stable and more inflammatory, suggesting that ABCG1 still functions as a protective transporter.

As described above, Abcgl deficiency in macrophages promotes apoptosis; however, its deletion in other hematopoietic cells results in hyperproliferation. Lymphocyte proliferation was found to be under the control of LXR which 


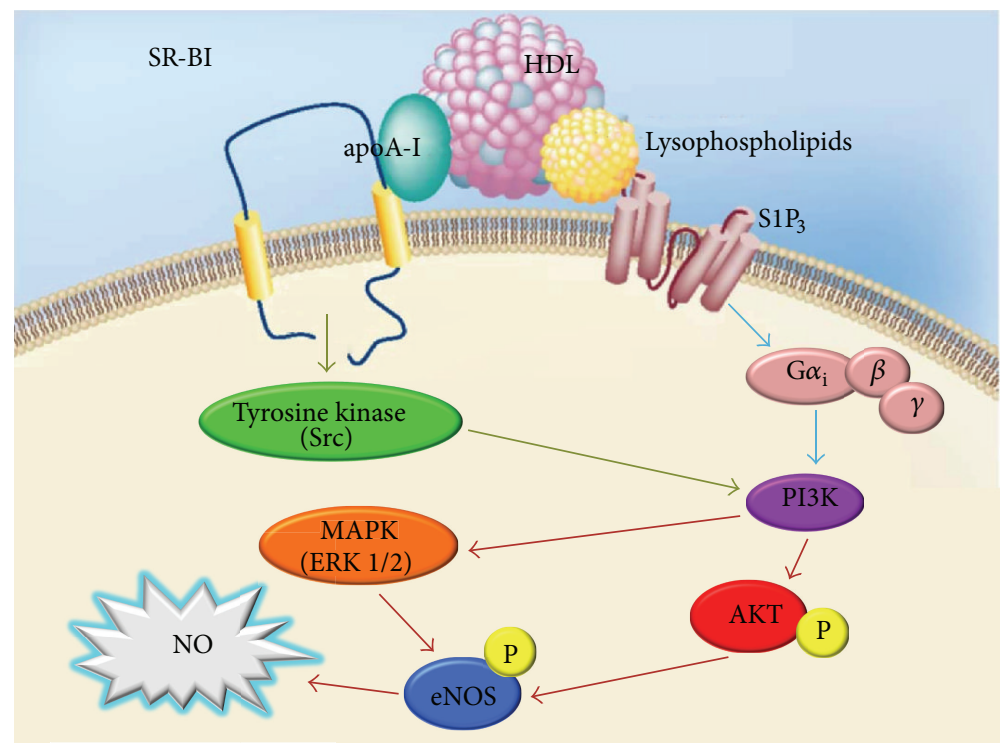

Figure 3: HDL signaling to eNOS through SR-B1 and $\mathrm{S}_{3}$. ApoA-I provokes a signalling cascade through SR-BI (green arrows) stimulating $\mathrm{PI} 3 \mathrm{~K}$ via Src. The lysophospholipids bind the $\mathrm{S}_{\mathrm{P}}{ }_{3}$ receptor and through the $\mathrm{G}$ proteins also stimulate PI3K (blue arrows). Cross-talk between the two pathways is depicted in red arrows implementing the involvement of Akt and MAPK amplifying the phosphorylation of eNOS.

modulates cellular cholesterol levels, in an ABCG1-dependent manner [117]. In line with this finding, Bensinger et al. found that lymphocyte proliferation was increased in $\mathrm{Abcgl}^{-/-}$mice [117]. Abcg1 deficiency also causes marked neutrophilia and monocytosis, attributable to the expansion and proliferation of hematopoietic stem and multipotential progenitor cells (HSPCs) $[115,118]$, where ABCG1 mediates efflux to HDL or HSPC-intrinsic apoE $[118,119]$.

4.4.6. Scavenger Receptor-B1. SR-B1 is a member of the B class scavenger receptors with high homology to CD36; however, these receptors play quite distinct roles in lipid metabolism and atherosclerosis [120-122]. SR-B1 has a large extracellular domain and two transmembrane domains with short $\mathrm{N}$ and C-terminal domains [123]. It is highly expressed in the liver and on macrophages [124] and has also been identified in other tissues and cells including the brain, intestine, endothelial cells, and astrocytes [125-127]. SR-B1 like CD36 has a number of ligands including modified and native LDL, VLDL, and HDL [121, 124]. However, SR-B1 also possesses the classical scavenger receptor abilities on phagocytic cells recognising apoptotic cells, advanced glycation endproducts (AGE), and oxidised phospholipids amongst other ligands, for removal from inflamed or necrotic tissue [128-130]. SRB1 plays an important role in cholesterol homeostasis by interacting with HDL. Of the various HDL subpopulations, SR-B1 can interact with discoidal HDL and spherical HDL, but it preferentially binds to the larger HDL species and has little to no affinity for lipid-poor apoA-I [121, 131-133]. After apoA-I takes on lipid and forms HDL, it undergoes conformational changes allowing the interaction with SR-B1 $[132,134,135]$. Distinct from other lipoprotein receptors, SRB1 displays bidirectional cholesterol transfer to HDL [124].
Therefore, SR-B1 has the ability to facilitate selective uptake $\mathrm{CE}$ and other lipids from both HDL and LDL into the cell, and either uptake or donate unesterified cholesterol [124, 136-142]. SR-B1 also contains a PDZK1-binding motif in the intracellular C-terminal tail which is critical for its expression on the plasma membrane [123]. HDL has also been shown to stimulate endothelial nitric oxide synthase (eNOS) and release NO [143], and it has been discovered that along with targeting SR-B1, the PDZK1 motif is required for HDL to signal to eNOS [144]. HDL through apoA-I binds to SR$\mathrm{B} 1$ to signal to Src inturn activating PI3K (Figure 3). While the lysophospholipids engage the sphingosine-1-phosphate $\left(\mathrm{SiP}_{3}\right)$ receptor also stimulating PI3K, which activate MAPKs and Akt phosphorylation of eNOS resulting in the production of NO, which is how HDL is thought to promote vasodilation [145].

\section{Anti-Inflammatory Effects of HDL}

It is well established that increased levels of HDL protect against atherosclerosis $[3,146]$. As discussed above, much of the atheroprotective effects of HDL stem from its capacity to remove cholesterol from extrahepatic tissues and to deliver it to the liver for disposal in a process commonly termed reverse cholesterol transport (RCT). However, other features of HDL, including stimulation of endothelial nitric oxide synthase (eNOS) and transforming growth factor- $\beta$ (TGF$\beta$ ), inhibition of the oxidation of LDL, and the release of proinflammatory molecules from a variety of cells, have been suggested to contribute to its beneficial effects [143, $147,148]$. HDL also regulates the expression of adhesion molecules on leukocytes and endothelial cells contributing to its anti-inflammatory properties. This data has received 
wide-spread interest particularly in view of the concept that atherosclerosis is an inflammatory disease [149, 150]. HDL has also been shown to act as an anticoagulant [151, 152].

\subsection{Anti-Inflammatory Effects of HDL}

5.1.1. Endothelial Cells. Endothelial function is essential for the regulation of blood flow and pressure via the release of soluble factors which regulate vascular tone. HDL has been implicated in the regulation of key molecules in this process on both the endothelial and circulating cells. In fact, HDL has been shown to protect against endothelial damage in a number of in vitro and in vivo models $[44,149,153]$.

One of the most potent roles of HDL on endothelial cells is to inhibit leukocyte adhesion. This was evident when endothelial cells were simulated with oxLDL in the presence or absence of HDL. Pretreatment of HDL resulted in a significant reduction in the adhesion of U937s (monocytic cells) [154]. Also, HDL has been consistently shown to reduce the expression of adhesion molecules in both endothelial cells and leukocytes $[149,150,155,156]$. This anti-inflammatory effect of HDL on endothelial cells is only observed by preincubating endothelial cells with HDL followed by stimulation with TNF- $\alpha$ [154]. Importantly, the inhibition by HDL appears time dependent: a preincubation for at least $30 \mathrm{mins}$ is required for an effective anti-inflammatory action. HDL does not appear to be able to reduce endothelial adhesion molecule expression after the endothelial cells have been activated.

C-reactive protein (CRP) has been demonstrated to have inflammatory actions on both leukocytes and endothelial cells $[157,158]$. Wadham et al. [159] demonstrated the ability of HDL to prevent endothelial cell activation and expression of adhesion molecules in response to CRP. This effect was shown to be mediated by PLs as PL vesicles, but not apoAI, was able to reduce the expression of adhesion molecules, suggesting that lipids may play a major role in this signalling event.

It is debatable as to which constituents of HDL play the key role in inhibiting the expression of adhesion molecules. As stated above, there is convincing evidence that lipid-free apoA-I can mimic some of the actions of HDL. However, several studies suggest that HDL-associated lysosphingolipids are capable of inhibiting adhesion molecule expression on endothelial cells $[160,161]$. Endothelial cells stimulated with TNF- $\alpha$ show a dramatic increase in the levels of th adhesion molecule E-selectin; this activation is significantly reduced when cells are preincubated with HDL. A similar reduction in cell activation was found when cells were treated with either sphingosylphosphorylcholine or lysosulfatide, the two lysosphingolipids associated with HDL [161], suggesting that these HDL constituents may be responsible for this effect.

5.1.2. Leukocytes. Adhesion of leukocytes to the vascular endothelium is mediated not only by endothelial adhesion molecules, but also by adhesion molecules expressed on leukocytes. We have shown that HDL and apoA-I decrease the activation of human primary monocytes and neutrophils
$[162,163]$. This effect was dependant on lipid removal and disruption of membrane lipid-rafts, resulting in the inhibition of a key leukocyte adhesion molecule CD11b. We also found that the decrease in leukocyte activation translated into reduced adhesion under settings of shear-flow to platelets and endothelial cells. ApoA-I has been shown to prevent the oxidative burst of neutrophils [164]. In this context, neutrophil degranulation and superoxide release stimulated by IgG were dose dependently inhibited by apoA-I [165]. Diederich and co-workers [166] discovered that cholesterol removal from monocytes using HDL, apoA-I, or cyclodextrin inhibits monocyte spreading under static conditions in response to Macrophage colony-stimulating factor (M-CSF). This appeared to be mediated through a decrease in celldivision cycle 42 (Cdc42) which may or may not be a result of a decrease in intracellular cholesterol. Taken together, HDL and apoA-I appear to inhibit monocyte differentiation into macrophages.

HDL and apoA-I can also indirectly protect leukocytes from activation during infection. This is thought to occur through the ability of both to bind and sequester LPS [167172]. In vivo studies conducted in mice and rats have demonstrated that both HDL and apoA-I can reduce leukocyte adhesion and protect against the inflammatory effects of LPS, largely thought to be mediated via the protein component of HDL (i.e., apoA-I) [172-174]. A study by Thaveeratitham et al. demonstrated that rHDL dose dependently decreases monocyte activation to LPS; however, this was not seen by mature HDL, giving further evidence that apoA-I may be the major protective molecule $[173,175]$.

Leukocytes are attracted to sites of vascular inflammation by chemokines. Bursill and co-workers discovered that administration of apoA-I in WTD fed $A p o e^{-/-}$mice reduced the plasma levels of CCL2 and CCL5. They also found that the chemokine receptors CCR2 and CX3CR1 expression in the atherosclerotic lesion was also reduced [176]. Incubation of monocytes with rHDL also reduced the expression of CCR2 and CX3CR1 suggesting that HDL suppresses the ability of the monocytes to sense chemokines involved in their recruitment to the atherosclerotic lesion.

Once monocytes leave the circulation and migrate into the atherosclerotic lesion, they can polarize into two main populations: M1-classically activated, or M2-alternatively activated. Studies in mice where atherosclerotic lesion regression was assessed using various methods to increase HDL levels have shown that inflammatory genes associated with M1 macrophages, such as TNF- $\alpha$, IL- $1 \beta$, and MCP-1, are down regulated, with a concomitant increased in genes associated with M2 macrophages including Arginase 1, Mannose Receptor, and IL-10 [177]. The ability of HDL to enhance macrophage polarization to the M2 population was recently shown. Sanson et al. found that incubation of mouse bone marrow derived macrophages when cultured in the presence of M2 promoting conditions (IL-4) and HDL had a more profound M2 phenotype compared to those cultured with IL-4 alone. Through the use of genetic knockout models, they showed that HDL was able to achieve this enhanced 
M2 polarization of macrophages by signaling through STAT6 [178]. Therefore, the ability of HDL to promote the polarization to the M2 phenotype could aid in the resolution of inflammation, and in the context of atherosclerosis promote lesion regression and stability. However, it is not clear if HDL can just influence macrophage polarization as the cell matures or if HDL can alter an already polarized macrophage. While the area of macrophage subsets remains controversial, perhaps it is more important to control the production of inflammatory cytokines from macrophages irrespective of the type of macrophage they are, as these are the signaling molecules that go one to modulate the immune response.

Hematopoiesis. Hematopoiesis is the term used to describe the production of the entire cell populations found in circulation that are derived from hematopoietic stem cells. Perhaps the most recent advance in our understanding of the role that cholesterol efflux and HDL plays is the regulation of hematopoiesis. This was discovered in a seminal study by Yvan-Charvet et al., where they observed profound leukocytosis, namely, of the myeloid lineage, in mice deficient in the 2 key cholesterol efflux transporters $\mathrm{ABACl}$ and $\mathrm{ABCG} 1$ [118]. It was found that deletion of these genes resulted in increased cholesterol rich regions in the membranes of the hematopoietic stem and multipotential progenitor cells (HSPCs) in the bone marrow. This leads to increased cell surface expression of the IL-3R common $\beta$-subunit, which forms a heterodimer with the IL-3R to sense the highly proliferative cytokine, IL-3. Overexpressing apoA-I using a transgene completely normalized these defects and returned leukocyte levels to the normal range. We later went on to discover that apoE was highly expressed in the HSPCs and deletion of Apoe also resulted in expansion of the HSPCs and myeloid blood cells [119]. This was found to be due to a cell intrinsic process as apoE is a key molecule in promoting cholesterol efflux from the cell it is expressed in via $A B C A 1$ and $A B C G 1$. When cholesterol efflux pathways were enhanced in the Apoe $e^{-/-}$mice, either by upregulating the $\mathrm{ABC}$ transporters by administration of an LXR agonist or infusion of rHDL, the myeloproliferative phenotype was suppressed.

Both the $A p o e^{-/-}$and the $A b c a 1^{-/-} / A b c g 1^{-/-}$mice also displayed extensive extramedullary hematopoiesis, that is, mobilization of HSPCs to the spleen where they actively produce monocytes and neutrophils $[118,119]$. This was also inhibited by the activation of cholesterol pathways in the respective models $[118,119]$. As HSPC mobilization to the spleen is the key initiating step in promoting extramedullary hematopoiesis, we investigated the role of the cholesterol efflux pathway in regulating HSPC mobilization from the bone marrow. This is an important aspect of CVD as it has recently been shown that the spleen is a major factory of the production of monocytes that can populate the atherosclerotic lesion [179]. Even more strikingly, postmyocardial infarction, the majority of the cells that are attracted to the infarct are splenic in origin and these cells also contribute to secondary events [180-182]. The mechanism behind the increased mobilization of HSPCs to the spleen was found to occur by the disruption of two key pathways, centered around an initial key event. Initially, defective cholesterol efflux from splenic macrophages and dendritic cells leads to the increased production of IL-23, which promoted the IL-23/IL-17/G-CSF signaling axis and enhanced production of neutrophils [183]. The G-CSF signaling to the bone marrow progenitor cells caused an imbalance in myeloid cell production, favoring the production of neutrophils over monocytic lineages. The over production of neutrophils then caused two important processes to occur. Firstly, the neutrophils provided a more proteolytic environment in the bone marrow, resulting in the cleavage of a key HSPC retention receptor CXCR4. Secondly, the lineage skewing away from monocytes/macrophages decreased that support network, reducing the CXCR4 ligand CXCL12 on mesenchymal stem cells and osteoblasts. Increasing HDL levels by the apoA-I transgene or infusion of rHDL reversed these processes. This was also examined in the fms-like tyrosine kinase receptor3 model of acute myeloid leukemia. Again, increasing HDL was able to suppress extramedullary hematopoiesis [183].

We have also recently discovered a role for HDL in regulating the production of platelets. Deletion of the cholesterol transporter $\mathrm{Abcg} 4$ resulted in increased atherosclerosis that was associated with thrombocytosis [184]. The mechanism was found to be due to enhanced signaling via c-MPL, the receptor of megakaryocyte progenitors cells (MkPs) that sense the key platelet production growth factor thrombopoietin (TPO). Deletion of Abcg4 resulted in increased cell membrane cholesterol and disruption of an important negative feedback loop for c-MPL. The Src kinase Lyn, which is usually phosphorylated after TPO binds c-MPL, was no longer able to phosphorylate and activate a key E3 ubiquitin ligase c-CBL that ubiquitinates c-MPL targeting it for degradation. With this pathway disrupted, more c-MPL was recycled to the surface of the MkPs, increasing surface levels and promoting more proliferative signaling. Infusion of rHDL to promote cholesterol efflux, which was uniquely ABCG4 dependent, normalized the proliferation of the MkPs and returned circulating platelet levels to normal.

We further explored the therapeutic potential of rHDL in reducing platelet production by examining the effects of rHDL infusion in a mouse model of myelofibrosis and essential thrombocytosis expressing a mutant form of $\mathrm{c}$ MPL (c-MPL ${ }^{\mathrm{W} 515 \mathrm{~L}}$ ), found in human myeloproliferative neoplasms $[185,186]$. Infusion of rHDL was able to reduce platelet levels in the c-MPL mutant expressing mice, again dependent on ABCG4. Together, these data suggest that HDL therapy has the ability to suppress extramedullary hematopoiesis, monocytosis, and thrombosis in models of atherosclerosis and myeloproliferative neoplasms.

5.1.3. Platelets. HDL has also been shown to have antithrombotic effects. Platelets express the full repertoire of HDL/apoA-I receptors (including ABCA1 [152] and SRB1 [187]) and interact with HDL and apoA-I [188-190]. HDL can inhibit thrombin induced platelet aggregation and fibrinogen binding [151]. The infusion of apoA- $\mathrm{I}_{\text {Milano }}$ in rats dramatically decreased thrombus formation compared to a 
vehicle control. This was demonstrated by time to thrombus formation, thrombus weight, and fibrin deposition [191]. The mechanism is yet to be confirmed but it is proposed that HDL/apoA-I may be directly causing decreases in second messengers such as 1,2 diacylglycerol (DAG), inositol 1,4,5-tris-phosphate, and intracellular calcium ([Ca $\left.]_{\mathrm{i}}\right)$ [151]. Another explanation could be that HDL/apoA-I acts on the endothelium to stimulate the release of NO which in turn can act on platelets $[188,190]$. In type 2 , diabetics infusion of rHDL significantly reduced platelet activation and aggregation [192]. As mentioned above, we have recently shown that HDL can also act upstream and control the production of platelets, which will also have important implications for its antiplatelet effects [184].

5.1.4. Other Roles in the Innate Immune Response Antiviral and Antibacterial. The protective roles of HDL/apoA-I may also extend to preventing viral and bacterial infections. Srinivas and co-workers demonstrated the antiviral capabilities of apoA-I included the reduction of viral yield and cell penetration [193]. Studies conducted in Oncorhynchus mykiss (Rainbow trout) have confirmed the expression of apoAI in some of the most important epithelial and mucosal layers [13]. HDL and apoA-I have also been demonstrated to have antimicrobial properties $[12,194]$ inhibiting the growth of Escherichia coli and Staphylococcus epidermidis [173, 195], a finding largely attributable to apoA-I. Another innate immune related role of apoA-I which was also discovered in fish is its regulation of the complement system [11].

5.2. Effects of Increasing HDL in Animal Models of Atherosclerosis. A number of studies using both mouse and rabbit models demonstrating the in vivo anti-inflammatory effects of HDL have been reported. Increasing apoA-I levels by, for example, the creation of Apoa-I transgenic mice on atherogenic backgrounds (Apoe $e^{-/-}$and $\mathrm{Ldlr}^{-/-}$) causes a decrease in plaque size and a restoration of vascular tone [196]. Conversely, the generation of Apoa- $I^{-/-}$mice have impaired reverse cholesterol transport, increased lesion size, and increased monocyte adhesion to endothelial cells [197]. Another interesting model demonstrating the antiinflammatory properties of HDL in rabbits was described by Nicholls et al. [153]. In this paper, the authors used a periarterial collar to induce infiltration of leukocytes into the arterial wall, an early event in the development of the atherosclerotic plaque. Infusion of rHDL or apoA-I inhibited the infiltration as well as the expression of VCAM-1 and ICAM-1. Furthermore, recent studies by Puranik and coworkers [198] showed that low levels of lipid-free apoAI administered up to 9 hours after nonocclusive collar injury to the carotid artery in rabbits "rescued" or halted the progression of inflammation by decreasing neutrophil activation and accumulation in the vessel wall. This has implications with regard to the importance of the antiinflammatory effects of apoA-I on circulating leukocytes. We explored the anti-inflammatory effects of apoA-I in vivo using intravital microscopy [163]. Administration of apoA-I to mice prestimulated with TNF- $\alpha$ resulted in decreased leukocyte adhesion to the endothelium and increased tethering and rolling velocity, suggesting that the leukocytes were "letting go" of the inflamed endothelium. This also correlated with a reduction in CD11b expression of the circulating neutrophils [163].

A separate development, briefly mentioned above, in the study of the antiatherogenic effect of HDL was the exciting discovery of the naturally occurring variant of apoA-

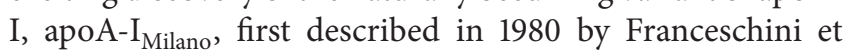
al. [43], who identified a family from Limone sur Garda, Italy, with a lipoprotein disorder resulting in abnormally low levels of HDL cholesterol. The intriguing nature of the finding was that despite the low HDL levels, this family exhibited no atherosclerosis. ApoA- $\mathrm{I}_{\text {Milano }}$ has since been well characterised and is a single amino acid mutation (Y192), favouring formation of dimers, shortened plasma half-life, and rapid catabolism of apoA-I [199]. The structural arrangement of apoA- $\mathrm{I}_{\text {Milano }}$ increases its affinity for lipids and facilitates its easy removal [200]. In apoE deficient mice, recombinant apoA- $\mathrm{I}_{\text {Milano }} / \mathrm{PL}$ complex significantly reduced aortic atherosclerosis, lipid content, and macrophage infiltration. ApoA- $\mathrm{I}_{\text {Milano }} / \mathrm{PL}$ also promoted cholesterol efflux significantly above basal levels [201]. Similar results were observed with apoA- $\mathrm{I}_{\text {Milano }}$ in Sprague Dawley rats [191] where apoA-I $\mathrm{I}_{\text {Milano }}$ reduced total and HDL cholesterol and platelet aggregation. In addition, chemical induced thrombosis was delayed and thrombus weight significantly reduced compared to control rats. These results provide compelling evidence for the therapeutic application of either apoA-I or apoA-I $\mathrm{I}_{\text {Milano }}$.

In addition to the regulation of adhesion molecules, there is an emerging role for HDL in endothelial repair where HDL has been shown to dose dependently facilitate endothelial cell migration in an in vitro wound model, a process which appears to be NO dependant [202]. The importance of both HDL and SR-B1 in endothelial repair was confirmed in vivo through the use of perivascular electric injury to the carotid artery of mice. This injury model was applied to both Apoa-I $I^{-/-}$and $S r b 1^{-/-}$mice, respectively. Both these mice displayed a diminished ability to repair the wounded endothelium, suggesting the importance of not only HDL but also of its receptor, SR-B1, and subsequent downstream signalling. The inability to repair the denuded endothelium was overcome by reexpressing either apoAI or SR-B1 [202]. This repair along with endothelial cell migration may also be attributed to the ability of HDL to stimulate the release of endothelial progenitor cells (EPC) into the circulation and stimulate TGF- $\beta$ release $[148,203]$. Tso and co-workers demonstrated the beneficial role that HDL plays in re-endothelialisation in mice injured with LPS. A significant increase in the proportion of aortic endothelial cells positive for Sca-1, a marker of EPCs, was observed after administration of rHDL. This was confirmed in a separate study employing an adenoviral transfer system of human apoA-I into Apoe $e^{-/-}$mice, demonstrating a clear increase in bone marrow-derived EPCs [204], which initiated an increase in endothelial repair evident by $\mathrm{CD}^{+} 1^{+}$endothelial cells [204]. Similarly, HDL increases TGF- $\beta_{2}$ expression in 
endothelial cells, an effect observed with treatment of apoAI or lysophospholipids [148]. Mice expressing human apoA-I had approximately 10 -fold increase in TGF- $\beta_{2}$ mRNA levels compared to Apoa- $I^{-1-}$ mice. This increase was attributed to the phosphorylation of ERK 1/2 and Akt. The increase in the TGF- $\beta$ signalling pathway activity was further supported by the increase in phosphorylation of Smad-2/3, an intracellular effector of TGF- $\beta$. Further to the stimulation of TGF- $\beta$, the enhanced abundance of EPCs following HDL treatment may be attributed to an increase in eNOS activation reducing EPC apoptosis through inhibition of caspase-3 [205]. However, the question arises, if HDL reduces adhesion molecule expression on both circulating leukocytes (presumably EPCs are included in this) and endothelial cells, then how are the EPCs recruited to the vessel wall?

In summary, these findings suggest that $\mathrm{HDL}$ is a potent anti-inflammatory agent, regulating cholesterol transport, NO, adhesion molecules, EPCs, and growth factors. The beneficial effects of HDL include promoting plaque stability to plaque regression, and extend to suppressing myeloid leukaemias, suggesting that raising HDL may therapeutically benefit multiple targets.

\section{High Density Lipoproteins in Disease}

Whilst HDL is regarded as an anti-inflammatory molecule, protecting against CVD, it can undergo modification altering its beneficial effects. There are a number of environmental factors which can contribute to the modification of HDL resulting in a defective/impaired molecule [206]. Such disease states include acute and chronic inflammation, CVD, hypercholesterolemia, and diabetes. Discussed below are some of the ways HDL can be modified and the functional implications of these modifications.

6.1. Oxidation/Chlorination. While disruption of the cholesterol efflux pathway leads to increased inflammatory responses $[115,118]$, inflammatory settings can also lead to impairment of the RCT pathway [207]. Using an in vivo model of RCT, it was shown that cholesterol efflux was significantly inhibited during inflammation. LPS induced inflammation resulted in increased plasma cholesterol levels largely attributed to increased LDL with no change in HDL [207]. In this setting, there was a moderate decrease in hepatic genes involved in cellular cholesterol movement including Abcal and Scarbl. However, the largest change appeared to be the remodelling of HDL, partitioning serum amyloid A into the particle while appearing to remove apoA-I [207].

It is now becoming apparent that the HDL particle itself can undergo a number of modifications in disease/inflammatory settings that impair its ability to facilitate RCT and carry out its known anti-inflammatory functions. The major culprit in modifying HDL appears to involve activated phagocytes secreting myeloperoxidase (MPO), which through chemical interactions modifies apoA-I. The most damaging modification is the addition of a chlorine to the tyrosine residue (Y192) [208]. Importantly, oxidized HDL has been found in the arterial walls of humans and HDL isolated from the atherosclerotic lesions of humans with established coronary artery disease had increased levels of chlorotyrosine compared to HDL isolated from the plasma of the same patients $[209,210]$. Further, plasma levels of chlorotyrosine were also increased in CAD patients compared to healthy subjects [211, 212]. The functional effects of apoA-I chlorination by the MPO system are clearly visible as a reduction in ABCA1 specific cholesterol efflux from macrophages [213215]. This occurs by impairing the initial stages of apoA-I interacting with $\mathrm{ABCA1}$ as chlorinated apoA-I fails to activate JAK-2, a key signalling pathway involved with enhanced binding apoA-I to ABCA1 $[102,216]$. As JAK-2 activation and cholesterol removal are required for the anti-inflammatory effects of apoA-I on macrophages, these findings would suggest that chlorinated apoA-I would have diminished antiinflammatory effects [217]. Recently, modification of apoAI has also been shown to occur by reactive carbonyls, namely, malondialdehyde (MDA) [218]. This modification also appears to occur in vivo as HDL isolated from human atherosclerotic lesions showed a distinct increase in MDAmodified HDL compared to the levels detected in HDL isolated from the plasma of healthy individuals. MDAmodified HDL had impaired cholesterol efflux capabilities providing another avenue for the generation of dysfunctional HDL in CVD.

6.2. Nonenzymatic Glycation. HDL does not only undergo oxidative modifications, but can also undergo nonenzymatic glycation in patients with type 2 diabetes mellitus [219]. Glycated HDL and apoA-I had significantly impaired cholesterol efflux from macrophages. In the case of glycated-apoAI, this appears to be related to decreased stabilization of ABCAl on the cell membrane possibly due to a decreased interaction between apoA-I and ABCA1 [219]. Additionally, the presence of advanced glycation end products (AGEs) can significantly attenuate ABCA1 and ABCG1 expression [220, 221]. Glycation of apoA-I also impairs its ability to interact with LCAT, which is crucial in the formation of mature HDL particles [222]. Taken together, the net result is a dramatic inhibition of the RCT system in diabetes.

Not only is the RCT system inhibited in diabetes but also so are the anti-inflammatory properties. Glycation of apoA-I results in a significant impairment of the ability of this lipoprotein to attenuate human monocyte activation as assessed by CD11b levels [219]. Using a model of in vivo inflammation in rabbits, it was discovered that glycated apoAI or rHDL could no longer inhibit neutrophil recruitment [223]. This was attributed to the inability of the cholesterol acceptors to inhibit the expression of endothelial adhesion molecules ICAM-1 and VCAM- 1 or reduce ROS at the site of inflammation. As apoA-I has recently been shown to potently attenuate neutrophil activation and recruitment to inflamed vasculature [163], it is likely that glycated apoA-I can no longer decrease neutrophil activation leading to the increased infiltration observed in this study. Clearly, the results suggest that the anti-inflammatory functions of HDL and apoA-I 
can be severely impaired in the setting of diabetes when modification by AGEs occurs.

\section{Perspective}

While there is a growing body of literature describing the cardioprotective effects of $\mathrm{HDL}$, we still have much to learn about this complex particle. HDL has generally been thought of as the "great hope" in treating CVD. Given the wide-ranging effects of HDL and the difficulty in observing clear improvement in cardiovascular outcomes in clinical evaluations of HDL raising therapies, it remains to be seen in which disease setting increasing HDL levels will be most efficient in reducing outcomes. However, it is important to note that clinical trials assessing HDL raising therapies to date have not disproven the HDL hypothesis, and by no means should HDL raising therapies be abandoned. As CVD is associated with an imbalance in plasma lipids, and HDL can promote reverse cholesterol transport, HDL has long been branded as a therapy for this disease. However, we are learning more about the functions of HDL and beginning to understand that regulating cholesterol levels can control the innate immune system. Evolutionary, this may be the primary role for HDL. There is certainly a strong rationale for HDL administration as an anti-inflammatory agent in diseases other than atherosclerosis. Moreover, the recent discoveries that HDL can inhibit hematopoietic progenitor cell proliferation and mobilization in models of leukaemia, which has opened up an exciting new avenue for potential diseases that may benefit from HDL. Perhaps now we need to extend our view on what type of patients we should be targeting with HDL therapy. It may turn out that people with particular types of CVD, diabetes, obesity, and so forth, are the ideal candidates for HDL raising therapies. However, it is entirely possible that HDL raising may be most effective in treating people with chronic inflammatory conditions where resolution of inflammation fails or diseases that are dependent on maintaining cellular cholesterol in order for cells to proliferate such as leukaemia. None the less, there is still much to be learnt about how to effectively raise HDL, what diseases to treat, and how this will impact on outcomes.

\section{Acknowledgments}

Andrew J. Murphy was supported by a grant from the Viertel Foundation, managed by ANZ Trustees and administered by the Diabetes Australia Research Trust. Dr. Amanda Sampson is thanked for her critical reading of the paper.

\section{References}

[1] C. J. Murray and A. D. Lopez, "Global mortality, disability, and the contribution of risk factors: global burden of disease study," The Lancet, vol. 349, no. 9063, pp. 1436-1442, 1997.

[2] R. J. Lefkowitz and J. T. Willerson, "Prospects for cardiovascular research," Journal of the American Medical Association, vol. 285, no. 5, pp. 581-587, 2001.

[3] T. Gordon, W. P. Castelli, and M. C. Hjortland, "High density lipoprotein as a protective factor against coronary heart disease.
The Framingham study," American Journal of Medicine, vol. 62, no. 5, pp. 707-714, 1977.

[4] B. F. Voight, G. Peloso, M. Orho-Melander et al., "Plasma HDL cholesterol and risk of myocardial infarction: a mendelian randomisation study," The Lancet, vol. 380, no. 9841, pp. 572580, 2012.

[5] A. V. Khera, M. Cuchel, M. De La Llera-Moya et al., "Cholesterol efflux capacity, high-density lipoprotein function, and atherosclerosis," New England Journal of Medicine, vol. 364, no. 2, pp. 127-135, 2011.

[6] F. J. Raal, G. J. Pilcher, R. Waisberg, E. P. Buthelezi, M. G. Veller, and B. I. Joffe, "Low-density lipoprotein cholesterol bulk is the pivotal determinant of atherosclerosis in familial hypercholesterolemia," American Journal of Cardiology, vol. 83, no. 9, pp. 1330-1333, 1999.

[7] R. Ross and L. Harker, "Hyperlipidemia and atherosclerosis. Chronic hyperlipidemia initiates and maintains lesions by endothelial cell desquamation and lipid accumulation," Science, vol. 193, no. 4258, pp. 1094-1100, 1976.

[8] J. P. Kane, M. J. Malloy, T. A. Ports, N. R. Phillips, J. C. Diehl, and R. J. Havel, "Regression of coronary atherosclerosis during treatment of familial hypercholesterolemia with combined drug regimens," Journal of the American Medical Association, vol. 264, no. 23, pp. 3007-3012, 1990.

[9] R. R. Packard and P. Libby, "Inflammation in atherosclerosis: from vascular biology to biomarker discovery and risk prediction," Clinical Chemistry, vol. 54, no. 1, pp. 24-38, 2008.

[10] K. Mizia-Stec, "Cvtokines and adhesive molecules in detection of endothelial dysfunction," Pharmacological Reports, vol. 58, pp. 21-32, 2006.

[11] B. Magnadóttir and S. Lange, "Is Apolipoprotein A-I a regulating protein for the complement system of cod (Gadus morhua L.)?" Fish and Shellfish Immunology, vol. 16, no. 2, pp. 265-269, 2004.

[12] M. I. Concha, S. Molina, C. Oyarzún, J. Villanueva, and R. Amthauer, "Local expression of apolipoprotein A-I gene and a possible role for HDL in primary defence in the carp skin," Fish and Shellfish Immunology, vol. 14, no. 3, pp. 259-273, 2003.

[13] F. Villarroel, A. Bastías, A. Casado, R. Amthauer, and M. I. Concha, "Apolipoprotein A-I, an antimicrobial protein in Oncorhynchus mykiss: evaluation of its expression in primary defence barriers and plasma levels in sick and healthy fish," Fish and Shellish Immunology, vol. 23, no. 1, pp. 197-209, 2007.

[14] M. Jensby Nielsen, L. Bo Nielsen, and S. K. Moestrup, "Highdensity lipoprotein and innate immunity," Future Lipidology, vol. 1, no. 6, pp. 729-734, 2006.

[15] D. D. Martin, M. S. Budamagunta, R. O. Ryan, J. C. Voss, and M. N. Oda, "Apolipoprotein A-I assumes a "looped belt" conformation on reconstituted high density lipoprotein," Journal of Biological Chemistry, vol. 281, no. 29, pp. 20418-20426, 2006.

[16] A. Catte, J. C. Patterson, M. K. Jones et al., "Novel changes in discoidal high density lipoprotein morphology: a molecular dynamics study," Biophysical Journal, vol. 90, no. 12, pp. 43454360, 2006.

[17] P. J. Blanche, E. L. Gong, T. M. Forte, and A. V. Nichols, "Characterization of human high-density lipoproteins by gradient gel electrophoresis," Biochimica et Biophysica Acta, vol. 665, no. 3, pp. 408-419, 1981.

[18] M. Pérusse, A. Pascot, J. Després, C. Couillard, and B. Lamarche, "A new method for HDL particle sizing by polyacrylamide gradient gel electrophoresis using whole plasma," Journal of Lipid Research, vol. 42, no. 8, pp. 1331-1334, 2001. 
[19] S. T. Kunitake, C. M. Mendel, and L. K. Hennessy, "Interconversion between apolipoprotein A-I-containing lipoproteins of pre- beta and alpha electrophoretic mobilities," Journal of Lipid Research, vol. 33, no. 12, pp. 1807-1816, 1992.

[20] B. C. Raphael, P. S. Dimick, and D. L. Puppione, "Electrophoretic characterization of bovine serum lipoproteins throughout gestation and lactation," Journal of Dairy Science, vol. 56, no. 11, pp. 1411-1414, 1973.

[21] F. Rezaee, B. Casetta, J. H. M. Levels, D. Speijer, and J. C. M. Meijers, "Proteomic analysis of high-density lipoprotein," Proteomics, vol. 6, no. 2, pp. 721-730, 2006.

[22] T. Vaisar, S. Pennathur, P. S. Green et al., "Shotgun proteomics implicates protease inhibition and complement activation in the antiinflammatory properties of HDL," Journal of Clinical Investigation, vol. 117, no. 3, pp. 746-756, 2007.

[23] G. Kostner and P. Alaupovic, "Studies of the composition and structure of plasma lipoproteins. Separation and quantification of the lipoprotein families occurring in the high density lipoproteins of human plasma," Biochemistry, vol. 11, no. 18, pp. 34193428, 1972.

[24] M. C. Cheung and J. J. Albers, "Distribution of high density lipoprotein particles with different apoprotein composition: particles with A-I and A-II and particles with A-I but no A-II," Journal of Lipid Research, vol. 23, no. 5, pp. 747-753, 1982.

[25] A. A. Ajees, G. M. Anantharamaiah, V. K. Mishra, M. M. Hussain, and H. M. K. Murthy, "Crystal structure of human apolipoprotein A-I: insights into its protective effect against cardiovascular diseases," Proceedings of the National Academy of Sciences of the United States of America, vol. 103, no. 7, pp. 2126-2131, 2006.

[26] T. L. Eggerman, J. M. Hoeg, M. S. Meng, A. Tombragel, D. Bojanovski, and H. B. Brewer Jr., "Differential tissue-specific expression of human apoA-I and apoA-II," Journal of Lipid Research, vol. 32, no. 5, pp. 821-828, 1991.

[27] J. P. Segrest, D. W. Garber, C. G. Brouillette, S. C. Harvey, and G. M. Anantharamaiah, "The amphipathic $\alpha$ helix: a multifunctional structural motif in plasma apolipoproteins," Advances in Protein Chemistry, vol. 45, pp. 303-369, 1994.

[28] P. Y. Chou and G. D. Fasman, "Prediction of the secondary structure of proteins from their amino acid sequence," Advances in Enzymology and Related Areas of Molecular Biology, vol. 47, pp. 45-148, 1978.

[29] J. Garnier, D. J. Osguthorpe, and B. Robson, "Analysis of the accuracy and implications of simple methods for predicting the secondary structure of globular proteins," Journal of Molecular Biology, vol. 120, no. 1, pp. 97-120, 1978.

[30] A. Jonas, K. E. Kezdy, and J. H. Wald, "Defined apolipoprotein A-I conformations in reconstituted high density lipoprotein discs," Journal of Biological Chemistry, vol. 264, no. 9, pp. 48184824, 1989.

[31] R. Brasseur, J. De Meutter, B. Vanloo, E. Goormaghtigh, J. M. Ruysschaert, and M. Rosseneu, "Mode of assembly of amphipathic helical segments in model high-density lipoproteins," Biochimica et Biophysica Acta, vol. 1043, no. 3, pp. 245-252, 1990.

[32] D. L. Sparks, M. C. Phillips, and S. Lund-Katz, "The conformation of apolipoprotein A-I in discoidal and spherical recombinant high density lipoprotein particles. 13C NMR studies of lysine ionization behavior," Journal of Biological Chemistry, vol. 267, no. 36, pp. 25830-25838, 1992.

[33] D. P. Rogers, C. G. Brouillette, J. A. Engler et al., "Truncation of the amine terminus of human apolipoprotein A-I substantially alters only the lipid-free conformation," Biochemistry, vol. 36, no. 2, pp. 288-300, 1997.

[34] L. M. Roberts, M. J. Ray, T. Shih, E. Hayden, M. M. Reader, and C. G. Brouillette, "Structural analysis of apolipoprotein A-I: limited proteolysis of methionine-reduced and -oxidized lipidfree and lipid-bound human apo A-I," Biochemistry, vol. 36, no. 24, pp. 7615-7624, 1997.

[35] S. E. Panagotopulos, E. M. Horace, J. N. Maiorano, and W. S. Davidson, "Apolipoprotein A-I adopts a belt-like orientation in reconstituted high density lipoproteins," Journal of Biological Chemistry, vol. 276, no. 46, pp. 42965-42970, 2001.

[36] R. Huang, R. Silva, W. Jerome et al., "Apolipoprotein A-I structural organization in high-density lipoproteins isolated from human plasma," Nature Structural \& Molecular Biology, vol. 18, no. 4, pp. 416-422, 2011.

[37] H. E. Miettinen, M. Jauhiainen, H. Gylling et al., "Apolipoprotein A-I(FIN) (Leu159 $\rightarrow$ Arg) mutation affects lecithin: cholesterol acyltransferase activation and subclass distribution of HDL but not cholesterol efflux from fibroblasts," Arteriosclerosis, Thrombosis, and Vascular Biology, vol. 17, no. 11, pp. 30213032, 1997.

[38] R. Miccoli, A. Bertolotto, R. Navalesi et al., "Compound heterozygosity for a structural apolipoprotein A-I variant, apo AI(L141R)(Pisa), and an apolipoprotein A-I null allele in patients with absence of HDL cholesterol, corneal opacifications, and coronary heart disease," Circulation, vol. 94, no. 7, pp. 1622-1628, 1996.

[39] K. H. Weisgraber, S. C. Rall Jr., and T. P. Bersot, "Apolipoprotein A-I(Milano). Detection of normal A-I in affected subjects and evidence for a cysteine for arginine substitution in the variant A-I," Journal of Biological Chemistry, vol. 258, no. 4, pp. 25082513, 1983.

[40] E. Bruckert, A. Von Eckardstein, H. Funke et al., "The replacement of arginine by cysteine at residue 151 in apolipoprotein A-I produces a phenotype similar to that of apolipoprotein AI(Milano)," Atherosclerosis, vol. 128, no. 1, pp. 121-128, 1997.

[41] L. Calabresi, G. Vecchio, F. Frigerio, L. Vavassori, C. R. Sirtoi, and G. Franceschini, "Reconstituted high-density lipoproteins with a disulfide-linked apolipoprotein A-I dimer: evidence for restricted particle size heterogeneity," Biochemistry, vol. 36, no. 41, pp. 12428-12433, 1997.

[42] U. Daum, C. Langer, A. Chirazi et al., "Apolipoprotein A$\mathrm{I}(\mathrm{R} 151 \mathrm{C})$ (Paris) is defective in activation of lecithin: cholesterol acyltransferase but not in initial lipid binding, formation of reconstituted lipoproteins, or promotion of cholesterol efflux," Journal of Molecular Medicine, vol. 77, no. 8, pp. 614-622, 1999.

[43] G. Franceschini, C. R. Sirtori, and A. Capurso, "A-I(Milano) apoprotein. Decreased high density lipoprotein cholesterol levels with significant lipoprotein modifications and without clinical atherosclerosis in an Italian family," Journal of Clinical Investigation, vol. 66, no. 5, pp. 892-900, 1980.

[44] S. E. Nissen, T. Tsunoda, E. M. Tuzcu et al., "Effect of recombinant ApoA-I Milano on coronary atherosclerosis in patients with acute coronary syndromes: a randomized controlled trial," Journal of the American Medical Association, vol. 290, no. 17, pp. 2292-2300, 2003.

[45] E. T. Alexander, G. L. Weibel, M. R. Joshi et al., "Macrophage reverse cholesterol transport in mice expressing ApoA-I Milano," Arteriosclerosis, Thrombosis, and Vascular Biology, vol. 29, no. 10, pp. 1496-1501, 2009.

[46] R. Miccoli, Y. Zhu, U. Daum et al., "A natural apolipoprotein AI variant, apoA-I(L141R)(Pisa), interferes with the formation of 
$\alpha$-high density lipoproteins (HDL) but not with the formation of $\operatorname{pr} \beta 1-H D L$ and influences efflux of cholesterol into plasma," Journal of Lipid Research, vol. 38, no. 6, pp. 1242-1253, 1997.

[47] H. E. Miettinen, H. Gylling, T. A. Miettinen, J. Viikari, L. Paulin, and K. Kontula, "Apolipoprotein A-I(Fin): dominantly inherited hypoalphalipoproteinemia due to a single base substitution in the apolipoprotein A-I gene," Arteriosclerosis, Thrombosis, and Vascular Biology, vol. 17, no. 1, pp. 83-90, 1997.

[48] R. Navalesi, R. Miccoli, L. Odoguardi et al., "Genetically determined absence of HDL-cholesterol and coronary atherosclerosis," The Lancet, vol. 346, no. 8976, pp. 708-709, 1995.

[49] J. McLean, C. Fielding, and D. Drayna, "Cloning and expression of human lecithin-cholesterol acyltransferase cDNA," Proceedings of the National Academy of Sciences of the United States of America, vol. 83, no. 8, pp. 2335-2339, 1986.

[50] C. J. Fielding, V. G. Shore, and P. E. Fielding, "A protein cofactor of lecithin: cholesterol acyltransferase," Biochemical and Biophysical Research Communications, vol. 46, no. 4, pp. 1493-1498, 1972.

[51] D. J. Gordon and B. M. Rifkind, "High-density lipoprotein-the clinical implications of recent studies," New England Journal of Medicine, vol. 321, no. 19, pp. 1311-1316, 1989.

[52] J. A. Kuivenhoven, A. F. Stalenhoef, J. S. Hill et al., “Two novel molecular defects in the LCAT gene are associated with fish eye disease," Arteriosclerosis, Thrombosis, and Vascular Biology, vol. 16, no. 2, pp. 294-303, 1996.

[53] J. E. Groener, A. J. Van Rozen, and D. W. Erkelens, "Cholesteryl ester transfer activity. Localization and role in distribution of cholesteryl ester among lipoproteins in man," Atherosclerosis, vol. 50, no. 3, pp. 261-271, 1984.

[54] A. S. Plump, L. Masucci-Magoulas, C. Bruce, C. L. Bisgaier, J. L. Breslow, and A. R. Tall, "Increased atherosclerosis in ApoE and LDL receptor gene knock-out mice as a result of human cholesteryl ester transfer protein transgene expression," Arteriosclerosis, Thrombosis, and Vascular Biology, vol. 19, no. 4, pp. 1105-1110, 1999.

[55] T. Gautier, D. Masson, M. C. Jong et al., "Apolipoprotein CI deficiency markedly augments plasma lipoprotein changes mediated by human cholesteryl ester transfer protein (CETP) in CETP transgenic/apoCI-knocked out mice," Journal of Biological Chemistry, vol. 277, no. 35, pp. 31354-31363, 2002.

[56] P. J. Barter, H. B. Brewer Jr., M. J. Chapman, C. H. Hennekens, D. J. Rader, and A. R. Tall, "Cholesteryl ester transfer protein: a novel target for raising HDL and inhibiting atherosclerosis," Arteriosclerosis, Thrombosis, and Vascular Biology, vol. 23, no. 2, pp. 160-167, 2003.

[57] L. K. Curtiss, D. J. Bonnet, and K. Rye, "The conformation of apolipoprotein A-I in high-density lipoproteins is influenced by core lipid composition and particle size: a surface plasmon resonance study," Biochemistry, vol. 39, no. 19, pp. 5712-5721, 2000.

[58] K. Rye and P. J. Barter, "Formation and metabolism of prebeta-migrating, lipid-poor apolipoprotein A-I," Arteriosclerosis, Thrombosis, and Vascular Biology, vol. 24, no. 3, pp. 421428, 2004.

[59] P. J. Barter, M. Caulfield, M. Eriksson et al., "Effects of torcetrapib in patients at high risk for coronary events," New England Journal of Medicine, vol. 357, no. 21, pp. 2109-2122, 2007.

[60] G. G. Schwartz, A. G. Olsson, M. Abt et al., "Effects of dalcetrapib in patients with a recent acute coronary syndrome," The New England Journal of Medicine, vol. 367, no. 22, pp. 20892099, 2012.
[61] C. P. Cannon, S. Shah, H. M. Dansky et al., "Safety of anacetrapib in patients with or at high risk for coronary heart disease," New England Journal of Medicine, vol. 363, no. 25, pp. 2406-2415, 2010.

[62] M.-C. Blatter Garin, C. Abbott, S. Messmer et al., "Quantification of human serum paraoxonase by enzyme linked immunoassay: population differences in protein concentrations," Biochemical Journal, vol. 304, no. 2, pp. 549-554, 1994.

[63] M. I. Mackness, S. Arrol, and P. N. Durrington, "Paraoxonase prevents accumulation of lipoperoxides in low-density lipoprotein," FEBS Letters, vol. 286, no. 1-2, pp. 152-154, 1991.

[64] S. Deakin, I. Leviev, M. Gomaraschi, L. Calabresi, G. Franceschini, and R. W. James, "Enzymatically active paraoxonase-1 is located at the external membrane of producing cells and released by a high affinity, saturable, desorption mechanism," Journal of Biological Chemistry, vol. 277, no. 6, pp. 4301-4308, 2002.

[65] M.-C. Blatter, R. W. James, S. Messner, F. Barja, and D. Pometta, "Identification of a distinct human high-density lipoprotein subspecies defined by a lipoprotein-associated protein, K45. Identity of K-45 with paraoxonase," European Journal of Biochemistry, vol. 211, no. 3, pp. 871-879, 1993.

[66] V. G. Cabana, C. A. Reardon, N. Feng, S. Neath, J. Lukens, and G. S. Getz, "Serum paraoxonase: effect of the apolipoprotein composition of HDL and the acute phase response," Journal of Lipid Research, vol. 44, no. 4, pp. 780-792, 2003.

[67] R. Zech, M. Rockseisen, K. Kluge, K. Dewald, V. W. Armstrong, and J. M. Chemnitius, "Lipoproteins and hydrolysis of organophosphorus compounds," Chemico-Biological Interactions, vol. 87, no. 1-3, pp. 85-94, 1993.

[68] A. Kontush, S. Chantepie, and M. J. Chapman, "Small, dense HDL particles exert potent protection of atherogenic LDL against oxidative stress," Arteriosclerosis, Thrombosis, and Vascular Biology, vol. 23, no. 10, pp. 1881-1888, 2003.

[69] J. Valabhji, A. J. McColl, M. Schachter, S. Dhanjil, W. Richmond, and R. S. Elkeles, "High-density lipoprotein composition and paraoxonase activity in type 1 diabetes," Clinical Science, vol. 101, no. 6, pp. 659-670, 2001.

[70] G. J. Kelso, W. D. Stuart, R. J. Richter, C. E. Furlong, T. C. JordanStarck, and J. A. K. Harmony, "Apolipoprotein J is associated with paraoxonase in human plasma," Biochemistry, vol. 33, no. 3, pp. 832-839, 1994.

[71] K. C. Vickers, B. T. Palmisano, B. M. Shoucri, R. D. Shamburek, and A. T. Remaley, "MicroRNAs are transported in plasma and delivered to recipient cells by high-density lipoproteins," Nature Cell Biology, vol. 13, no. 4, pp. 423-435, 2011.

[72] J. F. Oram, "HDL apolipoproteins and ABCA1 partners in the removal of excess cellular cholesterol," Arteriosclerosis, Thrombosis, and Vascular Biology, vol. 23, no. 5, pp. 720-727, 2003.

[73] R. M. Lawn, D. P. Wade, M. R. Garvin et al., "The Tangier disease gene product $\mathrm{ABCl}$ controls the cellular apolipoproteinmediated lipid removal pathway," Journal of Clinical Investigation, vol. 104, no. 8, pp. R25-R31, 1999.

[74] G. R. Castro and C. J. Fielding, "Early incorporation of cellderived cholesterol into pre- $\beta$-migrating high-density lipoprotein," Biochemistry, vol. 27, no. 1, pp. 25-29, 1988.

[75] B. F. Asztalos and P. S. Roheim, "Presence and formation of 'free apolipoprotein A-I-like' particles in human plasma," Arteriosclerosis, Thrombosis, and Vascular Biology, vol. 15, no. 9, pp. 1419-1423, 1995. 
[76] P. G. Frank and Y. L. Marcel, "Apolipoprotein A-I: structurefunction relationships," Journal of Lipid Research, vol. 41, no. 6, pp. 853-872, 2000.

[77] A. T. Remaley, U. K. Schumacher, J. A. Stonik, B. D. Farsi, H. Nazih, and H. B. Brewer Jr., "Decreased reverse cholesterol transport from tangier disease fibroblasts: acceptor specificity and effect of brefeldin on lipid efflux," Arteriosclerosis, Thrombosis, and Vascular Biology, vol. 17, no. 9, pp. 1813-1821, 1997.

[78] I. C. Gelissen, M. Harris, K. Rye et al., "ABCA1 and ABCG1 synergize to mediate cholesterol export to ApoA-I," Arteriosclerosis, Thrombosis, and Vascular Biology, vol. 26, no. 3, pp. 534-540, 2006.

[79] N. Wang, D. Lan, W. Chen, F. Matsuura, and A. R. Tall, "ATP-binding cassette transporters G1 and G4 mediate cellular cholesterol efflux to high-density lipoproteins," Proceedings of the National Academy of Sciences of the United States of America, vol. 101, no. 26, pp. 9774-9779, 2004.

[80] M. A. Kennedy, G. C. Barrera, K. Nakamura et al., "ABCG1 has a critical role in mediating cholesterol efflux to HDL and preventing cellular lipid accumulation," Cell Metabolism, vol. 1, no. 2, pp. 121-131, 2005.

[81] S. T. Thuahnai, S. Lund-Katz, P. Dhanasekaran et al., "Scavenger receptor class B type I-mediated cholesteryl ester-selective uptake and efflux of unesterified cholesterol: influence of high density lipoprotein size and structure," Journal of Biological Chemistry, vol. 279, no. 13, pp. 12448-12455, 2004.

[82] M. De La Llera-Moya, G. H. Rothblat, M. A. Connelly et al., "Scavenger receptor BI (SR-BI) mediates free cholesterol flux independently of HDL tethering to the cell surface," Journal of Lipid Research, vol. 40, no. 3, pp. 575-580, 1999.

[83] M. Dean, Y. Hamon, and G. Chimini, "The human ATPbinding cassette $(\mathrm{ABC})$ transporter superfamily," Journal of Lipid Research, vol. 42, no. 7, pp. 1007-1017, 2001.

[84] M. L. Fitzgerald, A. J. Mendez, K. J. Moore, L. P. Andersson, H. A. Panjeton, and M. W. Freeman, "ATP-binding cassette transporter Al contains an $\mathrm{NH} 2$-terminal signal anchor sequence that translocates the protein's first hydrophilic domain to the exoplasmic space," Journal of Biological Chemistry, vol. 276, no. 18, pp. 15137-15145, 2001.

[85] S. Bungert, L. L. Molday, and R. S. Molday, "Membrane topology of the ATP binding cassette transporter ABCR and its relationship to $\mathrm{ABC1}$ and related $\mathrm{ABCA}$ transporters: identification of N-linked glycosylation sites," Journal of Biological Chemistry, vol. 276, no. 26, pp. 23539-23546, 2001.

[86] K. Schwartz, R. M. Lawn, and D. P. Wade, "ABC1 gene expression and ApoA-I-mediated cholesterol efflux are regulated by LXR," Biochemical and Biophysical Research Communications, vol. 274, no. 3, pp. 794-802, 2000.

[87] Y. Uehara, S. Miura, A. von Eckardstein et al., "Unsaturated fatty acids suppress the expression of the ATP-binding cassette transporter G1 (ABCG1) and ABCA1 genes via an LXR/RXR responsive element," Atherosclerosis, vol. 191, no. 1, pp. 11-21, 2007.

[88] P. Costet, F. Lalanne, M. C. Gerbod-Giannone et al., "Retinoic acid receptor-mediated induction of ABCA1 in macrophages," Molecular and Cellular Biology, vol. 23, no. 21, pp. 7756-7766, 2003.

[89] J. F. Oram, "ATP-binding cassette transporter A1 and cholesterol trafficking," Current Opinion in Lipidology, vol. 13, no. 4, pp. 373-381, 2002.
[90] J. F. Oram and R. M. Lawn, "ABCA1: the gatekeeper for eliminating excess tissue cholesterol," Journal of Lipid Research, vol. 42, no. 8, pp. 1173-1179, 2001.

[91] Y. Takahashi and J. D. Smith, "Cholesterol efflux to apolipoprotein AI involves endocytosis and resecretion in a calciumdependent pathway," Proceedings of the National Academy of Sciences of the United States of America, vol. 96, no. 20, pp. 11358$11363,1999$.

[92] S. Santamarina-Fojo, A. T. Remaley, E. B. Neufeld, and J. Brewer H.B., "Regulation and intracellular trafficking of the ABCA1 transporter," Journal of Lipid Research, vol. 42, no. 9, pp. 13391345, 2001.

[93] L. Rohrer, C. Cavelier, S. Fuchs, M. A. Schlüter, W. Völker, and A. von Eckardstein, "Binding, internalization and transport of apolipoprotein A-I by vascular endothelial cells," Biochimica et Biophysica Acta, vol. 1761, no. 2, pp. 186-194, 2006.

[94] C. Cavelier, L. Rohrer, and A. Von Eckardstein, "ATP-binding cassette transporter A1 modulates apolipoprotein A-I transcytosis through aortic endothelial cells," Circulation Research, vol. 99, no. 10, pp. 1060-1066, 2006.

[95] E. B. Neufeld, A. T. Remaley, S. J. Demosky et al., "Cellular localization and trafficking of the human ABCA1 transporter," Journal of Biological Chemistry, vol. 276, no. 29, pp. 2758427590, 2001.

[96] E. B. Neufeld, J. A. Stonik, S. J. Demosky Jr. et al., “The ABCA1 transporter modulates late endocytic trafficking: insights from the correction of the genetic defect in Tangier disease," Journal of Biological Chemistry, vol. 279, no. 15, pp. 15571-15578, 2004.

[97] C. Vedhachalam, P. T. Duong, M. Nickel et al., "Mechanism of ATP-binding cassette transporter A1-mediated cellular lipid efflux to apolipoprotein A-I and formation of high density lipoprotein particles," Journal of Biological Chemistry, vol. 282, no. 34, pp. 25123-25130, 2007.

[98] L. O. Martinez, B. Agerholm-Larsen, N. Wang, W. Chen, and A. R. Tall, "Phosphorylation of a pest sequence in ABCA1 promotes calpain degradation and is reversed by ApoA-I," Journal of Biological Chemistry, vol. 278, no. 39, pp. 3736837374, 2003.

[99] N. Wang, W. Chen, P. Linsel-Nitschke et al., "A PEST sequence in $\mathrm{ABCA} 1$ regulates degradation by calpain protease and stabilization of ABCA1 by apoA-I," Journal of Clinical Investigation, vol. 111, no. 1, pp. 99-107, 2003.

[100] S. Roosbeek, F. Peelman, A. Verhee et al., "Phosphorylation by protein kinase CK2 modulates the activity of the ATP binding cassette A1 transporter," Journal of Biological Chemistry, vol. 279, no. 36, pp. 37779-37788, 2004.

[101] R. H. See, R. A. Caday-Malcolm, R. R. Singaraja et al., "Protein kinase A site-specific phosphorylation regulates ATP-binding cassette A1 (ABCA1)-mediated phospholipid efflux," Journal of Biological Chemistry, vol. 277, no. 44, pp. 41835-41842, 2002.

[102] C. Tang, A. M. Vaughan, and J. F. Oram, "Janus Kinase 2 modulates the apolipoprotein interactions with ABCA1 required for removing cellular cholesterol," Journal of Biological Chemistry, vol. 279, no. 9, pp. 7622-7628, 2004.

[103] Q. Li, M. Tsujita, and S. Yokoyama, "Selective down-regulation by protein kinase $\mathrm{C}$ inhibitors of apolipoprotein-mediated cellular cholesterol efflux in macrophages," Biochemistry, vol. 36, no. 40, pp. 12045-12052, 1997.

[104] A. J. Mendez, J. F. Oram, and E. L. Bierman, "Protein kinase C as a mediator of high density lipoprotein receptor-dependent efflux of intracellular cholesterol," Journal of Biological Chemistry, vol. 266, no. 16, pp. 10104-10111, 1991. 
[105] N. Theret, C. Delbart, G. Aguie, J. C. Fruchart, G. Vassaux, and G. Ailhaud, "Cholesterol efflux from adipose cells is coupled to diacylglycerol production and protein kinase C activation," Biochemical and Biophysical Research Communications, vol. 173, no. 3, pp. 1361-1368, 1990.

[106] M. Walter, H. Reinecke, J.-R. Nofer, U. Seedorf, and G. Assmann, "HDL3 stimulates multiple signaling pathways in human skin fibroblasts," Arteriosclerosis, Thrombosis, and Vascular Biology, vol. 15, no. 11, pp. 1975-1986, 1995.

[107] J. Jasmin, I. Mercier, F. Sotgia, and M. P. Lisanti, "SOCS proteins and caveolin-1 as negative regulators of endocrine signaling," Trends in Endocrinology and Metabolism, vol. 17, no. 4, pp. 150$158,2006$.

[108] L. Yvan-Charvet, M. Ranalletta, N. Wang et al., "Combined deficiency of $A B C A 1$ and $A B C G 1$ promotes foam cell accumulation and accelerates atherosclerosis in mice," Journal of Clinical Investigation, vol. 117, no. 12, pp. 3900-3908, 2007.

[109] M. Ranalletta, N. Wang, S. Han, L. Yvan-Charvet, C. Welch, and A. R. Tall, "Decreased atherosclerosis in low-density lipoprotein receptor knockout mice transplanted with $A b c g 1^{-/-}$bone marrow," Arteriosclerosis, Thrombosis, and Vascular Biology, vol. 26, no. 10, pp. 2308-2315, 2006.

[110] Á. Baldán, L. Pei, R. Lee et al., "Impaired development of atherosclerosis in hyperlipidemic $\mathrm{Ldlr}^{-/-}$and $A p o E^{-/-}$mice transplanted with $A b c g 1^{-/-}$bone marrow," Arteriosclerosis, Thrombosis, and Vascular Biology, vol. 26, no. 10, pp. 2301-2307, 2006.

[111] R. Out, M. Hoekstra, R. B. Hildebrand et al., "Macrophage ABCG1 deletion disrupts lipid homeostasis in alveolar macrophages and moderately influences atherosclerotic lesion development in LDL receptor-deficient mice," Arteriosclerosis, Thrombosis, and Vascular Biology, vol. 26, no. 10, pp. 2295-2300, 2006.

[112] I. Meurs, B. Lammers, Y. Zhao et al., "The effect of ABCG1 deficiency on atherosclerotic lesion development in LDL receptor knockout mice depends on the stage of atherogenesis," Atherosclerosis, vol. 221, no. 1, pp. 41-47, 2012.

[113] N. Terasaka, N. Wang, L. Yvan-Charvet, and A. R. Tall, "Highdensity lipoprotein protects macrophages from oxidized lowdensity lipoprotein-induced apoptosis by promoting efflux of 7-ketocholesterol via ABCG1," Proceedings of the National Academy of Sciences of the United States of America, vol. 104, no. 38, pp. 15093-15098, 2007.

[114] L. Yvan-Charvet, T. A. Pagler, T. A. Seimon et al., "ABCA1 and ABCG1 protect against oxidative stress-induced macrophage apoptosis during efferocytosis," Circulation Research, vol. 106, no. 12, pp. 1861-1869, 2010.

[115] L. Yvan-Charvet, C. Welch, T. A. Pagler et al., "Increased inflammatory gene expression in $\mathrm{ABC}$ transporter-deficient macrophages: free cholesterol accumulation, increased signaling via toll-like receptors, and neutrophil infiltration of atherosclerotic lesions," Circulation, vol. 118, no. 18, pp. 18371847, 2008.

[116] T. A. Pagler, M. Wang, M. Mondal et al., "Deletion of ABCA1 and ABCG1 impairs macrophage migration because of increased Racl signaling," Circulation Research, vol. 108, no. 2, pp. 194-200, 2011.

[117] S. J. Bensinger, M. N. Bradley, S. B. Joseph et al., "LXR signaling couples sterol metabolism to proliferation in the acquired immune response," Cell, vol. 134, no. 1, pp. 97-111, 2008.
[118] L. Yvan-Charvet, T. Pagler, E. L. Gautier et al., "ATP-binding cassette transporters and HDL suppress hematopoietic stem cell proliferation," Science, vol. 328, no. 5986, pp. 1689-1693, 2010.

[119] A. J. Murphy, M. Akhtari, S. Tolani et al., "ApoE regulates hematopoietic stem cell proliferation, monocytosis, and monocyte accumulation in atherosclerotic lesions in mice," Journal of Clinical Investigation, vol. 121, no. 10, pp. 4138-4149, 2011.

[120] N. R. Webb, W. J. S. De Villiers, P. M. Connell, F. C. De Beer, and D. R. Van Der Westhuyzen, "Alternative forms of the scavenger receptor BI (SR-BI)," Journal of Lipid Research, vol. 38, no. 7, pp. 1490-1495, 1997.

[121] S. L. Acton, P. E. Scherer, H. F. Lodish, and M. Krieger, "Expression cloning of SR-BI, a CD36-related class B scavenger receptor," Journal of Biological Chemistry, vol. 269, no. 33, pp. 21003-21009, 1994.

[122] D. Calvo and M. A. Vega, "Identification, primary structure, and distribution of CLA-1, a novel member of the CD36/LIMPII gene family," Journal of Biological Chemistry, vol. 268, no. 25, pp. 18929-18935, 1993.

[123] M. A. Connelly, M. De la Llera-Moya, P. Monzo et al., "Analysis of chimeric receptors shows that multiple distinct functional activities of scavenger receptor, class B, type I (SR-BI), are localized to the extracellular receptor domain," Biochemistry, vol. 40, no. 17, pp. 5249-5259, 2001.

[124] S. Acton, A. Rigotti, K. T. Landschulz, S. Xu, H. H. Hobbs, and M. Kriegert, "Identification of scavenger receptor SR-BI as a high density lipoprotein receptor," Science, vol. 271, no. 5248, pp. 518-520, 1996.

[125] S. W. Altmann, H. R. Davis Jr., X. Yao et al., “The identification of intestinal scavenger receptor class B, type I (SR-BI) by expression cloning and its role in cholesterol absorption," Biochimica et Biophysica Acta, vol. 1580, no. 1, pp. 77-93, 2002.

[126] J. Husemann and S. C. Silverstein, "Expression of scavenger receptor class B, type I, by astrocytes and vascular smooth muscle cells in normal adult mouse and human brain and in Alzheimer's disease brain," American Journal of Pathology, vol. 158, no. 3, pp. 825-832, 2001.

[127] R. A. Srivastava, "Scavenger receptor class B type I expression in murine brain and regulation by estrogen and dietary cholesterol," Journal of the Neurological Sciences, vol. 210, no. 1, pp. 111128, 2003.

[128] A. Rigotti, S. L. Acton, and M. Krieger, “The class B scavenger receptors SR-BI and CD36 are receptors for anionic phospholipids," Journal of Biological Chemistry, vol. 270, no. 27, pp. 16221-16224, 1995.

[129] K. Murao, V. Terpstra, S. R. Green, N. Kondratenko, D. Steinberg, and O. Quehenberger, "Characterization of CLA-1, a human homologue of rodent scavenger receptor BI, as a receptor for high density lipoprotein and apoptotic thymocytes," Journal of Biological Chemistry, vol. 272, no. 28, pp. 17551-17557, 1997.

[130] C. Cheng, K. Tsuneyama, H. Zheng et al., "Enhanced scavenging of lipid substances is a possible effect of corticosteroids in the treatment of cholesterol crystal embolism," Pathology Research and Practice, vol. 202, no. 8, pp. 591-598, 2006.

[131] M. Krieger, "Scavenger receptor class b type I is a multiligand hdl receptor that influences diverse physiologic systems," Journal of Clinical Investigation, vol. 108, no. 6, pp. 793-797, 2001.

[132] K. N. Liadaki, T. Liu, S. Xu et al., "Binding of high density lipoprotein (HDL) and discoidal reconstituted HDL to the $\mathrm{HDL}$ receptor scavenger receptor class $\mathrm{B}$ type $\mathrm{I}$ : effect of 
lipid association and APOA-I mutations on receptor binding," Journal of Biological Chemistry, vol. 275, no. 28, pp. 21262-21271, 2000.

[133] S. Xu, M. Laccotripe, X. Huang, A. Rigotti, V. I. Zannis, and M. Krieger, "Apolipoproteins of HDL can directly mediate binding to the scavenger receptor SR-BI, an HDL receptor that mediates selective lipid uptake," Journal of Lipid Research, vol. 38, no. 7, pp. 1289-1298, 1997.

[134] M. C. De Beer, D. M. Durbin, L. Cai, A. Jonas, F. C. De Beer, and D. R. Van der Westhuyzen, "Apolipoprotein A-I conformation markedly influences HDL interaction with scavenger receptor BI," Journal of Lipid Research, vol. 42, no. 2, pp. 309-313, 2001.

[135] D. L. Williams, M. De La Llera-Moya, S. T. Thuahnai et al., "Binding and cross-linking studies show that scavenger receptor BI interacts with multiple sites in apolipoprotein A-I and identify the class A amphipathic $\alpha$-helix as a recognition motif," Journal of Biological Chemistry, vol. 275, no. 25, pp. 18897-18904, 2000.

[136] P. G. Yancey, M. De La Llera-Moya, S. Swarnakar et al., "High density lipoprotein phospholipid composition is a major determinant of the bi-directional flux and net movement of cellular free cholesterol mediated by scavenger receptor BI," Journal of Biological Chemistry, vol. 275, no. 47, pp. 3659636604, 2000.

[137] S. Urban, S. Zieseniss, M. Werder, H. Hauser, R. Budzinski, and B. Engelmann, "Scavenger receptor BI transfers major lipoprotein-associated phospholipids into the cells," Journal of Biological Chemistry, vol. 275, no. 43, pp. 33409-33415, 2000.

[138] S. T. Thuahnai, S. Lund-Katz, D. L. Williams, and M. C. Phillips, "Scavenger receptor class B, type I-mediated uptake of various lipids into cells: influence of the nature of the donor particle interaction with the receptor," Journal of Biological Chemistry, vol. 276, no. 47, pp. 43801-43808, 2001.

[139] D. J. Greene, J. W. Skeggs, and R. E. Morton, "Elevated triglyceride content diminishes the capacity of high density lipoprotein to deliver cholesteryl esters via the scavenger receptor class B type I (SR-BI)," Journal of Biological Chemistry, vol. 276, no. 7, pp. 4804-4811, 2001.

[140] H. Stangl, M. Hyatt, and H. H. Hobbs, "Transport of lipids from high and low density lipoproteins via scavenger receptorBI," Journal of Biological Chemistry, vol. 274, no. 46, pp. 3269232698, 1999.

[141] S. Swarnakar, R. E. Temel, M. A. Connelly, S. Azhar, and D. L. Williams, "Scavenger receptor class B, type I, mediates selective uptake of low density lipoprotein cholesteryl ester," Journal of Biological Chemistry, vol. 274, no. 42, pp. 29733-29739, 1999.

[142] X. Gu, K. Kozarsky, and M. Krieger, "Scavenger receptor class $\mathrm{B}$, type I-mediated $[3 \mathrm{H}]$ cholesterol efflux to high and low density lipoproteins is dependent on lipoprotein binding to the receptor," Journal of Biological Chemistry, vol. 275, no. 39, pp. 29993-30001, 2000.

[143] I. S. Yuhanna, Y. Zhu, B. E. Cox et al., "High-density lipoprotein binding to scavenger receptor-BI activates endothelial nitric oxide synthase," Nature Medicine, vol. 7, no. 7, pp. 853-857, 2001.

[144] C. Assanasen, C. Mineo, D. Seetharam et al., "Cholesterol binding, efflux, and a PDZ-interacting domain of scavenger receptor-BI mediate HDL-initiated signaling," Journal of Clinical Investigation, vol. 115, no. 4, pp. 969-977, 2005.

[145] A. J. Murphy, D. Sviridov, and J. P. Chin-Dusting, "Lipids and the endothelium: an update," Future Lipidology, vol. 1, no. 5, pp. 517-526, 2006.
[146] W. P. Castelli, R. J. Garrison, and P. W. F. Wilson, "Incidence of coronary heart disease and lipoprotein cholesterol levels. The Framingham Study," Journal of the American Medical Association, vol. 256, no. 20, pp. 2835-2838, 1986.

[147] M. Navab, J. A. Berliner, G. Subbanagounder et al., "HDL and the inflammatory response induced by LDL-derived oxidized phospholipids," Arteriosclerosis, Thrombosis, and Vascular Biology, vol. 21, no. 4, pp. 481-488, 2001.

[148] G. D. Norata, E. Callegari, M. Marchesi, G. Chiesa, P. Eriksson, and A. L. Catapano, "High-density lipoproteins induce transforming growth factor- $\beta 2$ expression in endothelial cells," Circulation, vol. 111, no. 21, pp. 2805-2811, 2005.

[149] G. W. Cockerill, K.-A. Rye, J. R. Gamble, M. A. Vadas, and P. J. Barter, "High-density lipoproteins inhibit cytokine-induced expression of endothelial cell adhesion molecules," Arteriosclerosis, Thrombosis, and Vascular Biology, vol. 15, no. 11, pp. 19871994, 1995.

[150] R. Moudry, M. O. Spycher, and J. E. Doran, "Reconstituted high density lipoprotein modulates adherence of polymorphonuclear leukocytes to human endothelial cells," Shock, vol. 7, no. 3, pp. 175-181, 1997.

[151] J. Nofer, M. Walter, B. Kehrel et al., "HDL3-mediated inhibition of thrombin-induced platelet aggregation and fibrinogen binding occurs via decreased production of phosphoinositidederived second messengers 1,2-diacylglycerol and inositol 1,4,5tris- phosphate," Arteriosclerosis, Thrombosis, and Vascular Biology, vol. 18, no. 6, pp. 861-869, 1998.

[152] S. Barlage, D. Boettcher, A. Boettcher, A. Dada, and G. Schmitz, "High density lipoprotein modulates platelet function," Cytometry Part A, vol. 69, no. 3, pp. 196-199, 2006.

[153] S. J. Nicholls, G. J. Dusting, B. Cutri et al., "Reconstituted high-density lipoproteins inhibit the acute pro-oxidant and proinflammatory vascular changes induced by a periarterial collar in normocholesterolemic rabbits," Circulation, vol.111, no. 12, pp. 1543-1550, 2005.

[154] J. A. M. Maier, L. Barenghi, F. Pagani, S. Bradamante, P. Comi, and G. Ragnotti, "The protective role of high-density lipoprotein on oxidized-low-density-lipoprotein-induced U937/ endothelial cell interactions," European Journal of Biochemistry, vol. 221, no. 1, pp. 35-41, 1994.

[155] P. Cettour-Rose, T. X. K. Nguyen, L. Serrander et al., “T cell contact-mediated activation of respiratory burst in human polymorphonuclear leukocytes is inhibited by high-density lipoproteins and involves CD18," Journal of Leukocyte Biology, vol. 77, no. 1, pp. 52-58, 2005.

[156] M. Navab, S. S. Imes, S. Y. Hama et al., "Monocyte transmigration induced by modification of low density lipoprotein in cocultures of human aortic wall cells is due to induction of monocyte chemotactic protein 1 synthesis and is abolished by high density lipoprotein," Journal of Clinical Investigation, vol. 88, no. 6, pp. 2039-2046, 1991.

[157] D. Kawanami, K. Maemura, N. Takeda et al., "C-reactive protein induces VCAM-1 gene expression through NF- $\kappa$ B activation in vascular endothelial cells," Atherosclerosis, vol. 185, no. 1, pp. 3946, 2006.

[158] K. J. Woollard, D. C. Phillips, and H. R. Griffiths, "Direct modulatory effect of C-reactive protein on primary human monocyte adhesion to human endothelial cells," Clinical and Experimental Immunology, vol. 130, no. 2, pp. 256-262, 2002.

[159] C. Wadham, N. Albanese, J. Roberts et al., "High-density lipoproteins neutralize C-reactive protein proinflammatory activity," Circulation, vol. 109, no. 17, pp. 2116-2122, 2004. 
[160] T. Kimura, H. Tomura, C. Mogi et al., "Sphingosine 1-phosphate receptors mediate stimulatory and inhibitory signalings for expression of adhesion molecules in endothelial cells," Cellular Signalling, vol. 18, no. 6, pp. 841-850, 2006.

[161] J. Nofer, S. Geigenmüller, C. Göpfert, G. Assmann, E. Buddecke, and A. Schmidt, "High density lipoprotein-associated lysosphingolipids reduce E-selectin expression in human endothelial cells," Biochemical and Biophysical Research Communications, vol. 310, no. 1, pp. 98-103, 2003.

[162] A. J. Murphy, K. J. Woollard, A. Hoang et al., "Highdensity lipoprotein reduces the human monocyte inflammatory response," Arteriosclerosis, Thrombosis, and Vascular Biology, vol. 28, no. 11, pp. 2071-2077, 2008.

[163] A. J. Murphy, K. J. Woollard, A. Suhartoyo et al., "Neutrophil activation is attenuated by high-density lipoprotein and apolipoprotein A-I in in vitro and in vivo models of inflammation," Arteriosclerosis, Thrombosis, and Vascular Biology, vol. 31, no. 6, pp. 1333-1341, 2011.

[164] X. Liao, B. Lou, J. Ma, and M. Wu, "Neutrophils activation can be diminished by apolipoprotein A-I," Life Sciences, vol. 77, no. 3, pp. 325-335, 2005.

[165] W. D. Blackburn Jr., J. G. Dohlman, Y. V. Venkatachalapathi et al., "Apolipoprotein A-I decreases neutrophil degranulation and superoxide production," Journal of Lipid Research, vol. 32, no. 12, pp. 1911-1918, 1991.

[166] W. Diederich, E. Orsó, W. Drobnik, and G. Schmitz, "Apolipoprotein AI and HDL3 inhibit spreading of primary human monocytes through a mechanism that involves cholesterol depletion and regulation of CDC42," Atherosclerosis, vol. 159, no. 2, pp. 313-324, 2001.

[167] J. Ma, X. L. Liao, B. Lou, and M. P. Wu, "Role of apolipoprotein A-I in protecting against endotoxin toxicity," Acta Biochimica et Biophysica Sinica, vol. 36, no. 6, pp. 419-424, 2004.

[168] M. F. Henning, H. A. Garda, and L. Bakas, "Biophysical characterization of interaction between apolipoprotein A-I and bacterial lipopolysaccharide," Cell Biochemistry and Biophysics, vol. 44, no. 3, pp. 490-496, 2006.

[169] D. Pajkrt, J. E. Doran, F. Koster et al., "Antiinflammatory effects of reconstituted high-density lipoprotein during human endotoxemia," Journal of Experimental Medicine, vol. 184, no. 5, pp. 1601-1608, 1996.

[170] K. Brandenburg, G. Jürgens, J. Andrä et al., "Biophysical characterization of the interaction of high-density lipoprotein (HDL) with endotoxins," European Journal of Biochemistry, vol. 269, no. 23, pp. 5972-5981, 2002.

[171] H. J. Van Leeuwen, A. P. Van Beek, G. M. Dallinga-Thie, J. A. G. Van Strijp, J. Verhoef, and K. P. M. Van Kessel, “The role of high density lipoprotein in sepsis," Netherlands Journal of Medicine, vol. 59, no. 3, pp. 102-110, 2001.

[172] D. M. Levine, T. S. Parker, T. M. Donnelly, A. Walsh, and A. L. Rubin, "In Vivo protection against endotoxin by plasma high density lipoprotein," Proceedings of the National Academy of Sciences of the United States of America, vol. 90, no. 24, pp. 12040-12044, 1993.

[173] P. Thaveeratitham, W. Plengpanich, W. Naen-Udorn, S. Patumraj, and W. Khovidhunkit, "Effects of human apolipoprotein A-I on endotoxin-induced leukocyte adhesion on endothelial cells in vivo and on the growth of Escherichia coli in vitro," Journal of Endotoxin Research, vol. 13, no. 1, pp. 58-64, 2007.
[174] P. Thaveeratitham, W. Khovidhunkit, and S. Patumraj, "Highdensity lipoproteins (HDL) inhibit endotoxin-induced leukocyte adhesion on endothelial cells in rats: effect of the acutephase HDL," Clinical Hemorheology and Microcirculation, vol. 36, no. 1, pp. 1-12, 2007.

[175] P. A. Thompson and R. L. Kitchens, "Native high-density lipoprotein augments monocyte responses to lipopolysaccharide (LPS) by suppressing the inhibitory activity of LPS-binding protein," Journal of Immunology, vol. 177, no. 7, pp. 4880-4887, 2006.

[176] C. A. Bursill, M. L. Castro, D. T. Beattie et al., "High-density lipoproteins suppress chemokines and chemokine receptors in vitro and in vivo," Arteriosclerosis, Thrombosis, and Vascular Biology, vol. 30, no. 9, pp. 1773-1778, 2010.

[177] J. E. Feig, J. X. Rong, R. Shamir et al., "HDL promotes rapid atherosclerosis regression in mice and alters inflammatory properties of plaque monocyte-derived cells," Proceedings of the National Academy of Sciences of the United States of America, vol. 108, no. 17, pp. 7166-7171, 2011.

[178] M. Sanson, E. Distel, and E. A. Fisher, "HDL induces the expression of the M2 macrophage markers arginase 1 and Fizz-1 in a STAT6-dependent process," PLoS ONE, vol. 8, no. 8, Article ID e74676, 2013.

[179] C. S. Robbins, A. Chudnovskiy, P. J. Rauch et al., "Extramedullary hematopoiesis generates Ly-6Chigh monocytes that infiltrate atherosclerotic lesions," Circulation, vol. 125, no. 2, pp. 364-374, 2012.

[180] F. Leuschner, P. J. Rauch, T. Ueno et al., "Rapid monocyte kinetics in acute myocardial infarction are sustained by extramedullary monocytopoiesis," Journal of Experimental Medicine, vol. 209, no. 1, pp. 123-137, 2012.

[181] F. K. Swirski, M. Nahrendorf, M. Etzrodt et al., "Identification of splenic reservoir monocytes and their deployment to inflammatory sites," Science, vol. 325, no. 5940, pp. 612-616, 2009.

[182] P. Dutta, G. Courties, Y. Wei et al., "Myocardial infarction accelerates atherosclerosis," Nature, vol. 487, no. 7407, pp. 325329, 2012.

[183] M. Westerterp, S. Gourion-Arsiquaud, A. J. Murphy et al., "Regulation of hematopoietic stem and progenitor cell mobilization by cholesterol efflux pathways," Cell Stem Cell, vol. 11, no. 2, pp. 195-206, 2012.

[184] A. J. Murphy, N. Bijl, L. Yvan-Charvet et al., "Cholesterol efflux in megakaryocyte progenitors suppresses platelet production and thrombocytosis," Nature Medicine, vol. 19, no. 5, pp. 586594, 2013.

[185] Y. Pikman, B. H. Lee, T. Mercher et al., "MPLW515L is a novel somatic activating mutation in myelofibrosis with myeloid metaplasia," PLoS Medicine, vol. 3, no. 7, pp. 1140-1151, 2006.

[186] P. Koppikar, O. Abdel-Wahab, C. Hedvat et al., "Efficacy of the JAK2 inhibitor INCB16562 in a murine model of MPLW515Linduced thrombocytosis and myelofibrosis," Blood, vol. 115, no. 14, pp. 2919-2927, 2010.

[187] H. Imachi, K. Murao, W. Cao et al., "Expression of human scavenger receptor B1 on and in human platelets," Arteriosclerosis, Thrombosis, and Vascular Biology, vol. 23, no. 5, pp. 898-904, 2003.

[188] S. J. A. Korporaal and J. N. Akkerman, "Platelet activation by low density lipoprotein and high density lipoprotein," Pathophysiology of Haemostasis and Thrombosis, vol. 35, no. 3-4, pp. 270-280, 2006.

[189] D. Ozsavci, T. Yardimci, G. Y. Demirel, F. Uras, N. Hekim, and N. U. Ulutin, "Apo A-I binding to platelets detected by flow 
cytometry," Thrombosis Research, vol. 103, no. 2, pp. 117-122, 2001.

[190] G. Schmitz and C. M. Schambeck, "Molecular defects in the ABCAl pathway affect platelet function," Pathophysiology of Haemostasis and Thrombosis, vol. 35, no. 1-2, pp. P166-P174, 2006.

[191] D. Li, S. Weng, B. Yang et al., "Inhibition of arterial thrombus formation by ApoA1 Milano," Arteriosclerosis, Thrombosis, and Vascular Biology, vol. 19, no. 2, pp. 378-383, 1999.

[192] A. C. Calkin, B. G. Drew, A. Ono et al., "Reconstituted highdensity lipoprotein attenuates platelet function in individuals with type 2 diabetes mellitus by promoting cholesterol efflux," Circulation, vol. 120, no. 21, pp. 2095-2104, 2009.

[193] R. V. Srinivas, B. Birkedal, R. J. Owens, G. M. Anantharamaiah, J. P. Segrest, and R. W. Compans, "Antiviral effects of apolipoprotein A-I and its synthetic amphipathic peptide analogs," Virology, vol. 176, no. 1, pp. 48-57, 1990.

[194] M. I. Concha, V. J. Smith, K. Castro, A. Bastías, A. Romero, and R. J. Amthauer, "Apolipoproteins A-I and A-II are potentially important effectors of innate immunity in the teleost fish Cyprinus carpio," European Journal of Biochemistry, vol. 271, no. 14, pp. 2984-2990, 2004.

[195] N. Tada, T. Sakamoto, A. Kagami, K. Mochizuki, and K. Kurosaka, "Antimicrobial activity of lipoprotein particles containing apolipoprotein Al," Molecular and Cellular Biochemistry, vol. 119, no. 1-2, pp. 171-178, 1993.

[196] D. T. Valenta, J. J. Bulgrien, C. L. Banka, and L. K. Curtiss, "Overexpression of human ApoAI transgene provides long-term atheroprotection in LDL receptor-deficient mice," Atherosclerosis, vol. 189, no. 2, pp. 255-263, 2006.

[197] R. E. Moore, M. Navab, J. S. Millar et al., "Increased atherosclerosis in mice lacking apolipoprotein A-I attributable to both impaired reverse cholesterol transport and increased inflammation," Circulation Research, vol. 97, no. 8, pp. 763-771, 2005.

[198] R. Puranik, S. Bao, E. Nobecourt et al., "Low dose apolipoprotein A-I rescues carotid arteries from inflammation in vivo," Atherosclerosis, vol. 196, no. 1, pp. 240-247, 2008.

[199] P. Roma, R. E. Gregg, M. S. Meng et al., "In Vivo metabolism of a mutant form of apolipoprotein A-I, apo A- I(Milano), associated with familial hypoalphalipoproteinemia," Journal of Clinical Investigation, vol. 91, no. 4, pp. 1445-1452, 1993.

[200] G. Franceschini, G. Vecchio, and G. Gianfranceschi, "Apolipoprotein AI(Milano). Accelerated binding and dissociation from lipids of a human apolipoprotein variant," Journal of Biological Chemistry, vol. 260, no. 30, pp. 16321-16325, 1985.

[201] P. K. Shah, J. Nilsson, S. Kaul et al., "Effects of recombinant apolipoprotein A-I(Milano) on aortic atherosclerosis in apolipoprotein E-deficient mice," Circulation, vol. 97, no. 8, pp. 780-785, 1998.

[202] D. Seetharam, C. Mineo, A. K. Gormley et al., "High-density lipoprotein promotes endothelial cell migration and reendothelialization via scavenger receptor-B type I," Circulation Research, vol. 98, no. 1, pp. 63-72, 2006.

[203] C. Tso, G. Martinic, W. Fan, C. Rogers, K. Rye, and P. J. Barter, "High-density lipoproteins enhance progenitormediated endothelium repair in mice," Arteriosclerosis, Thrombosis, and Vascular Biology, vol. 26, no. 5, pp. 1144-1149, 2006.

[204] Y. Feng, F. Jacobs, E. V. Craeyveld et al., "Human ApoAI transfer attenuates transplant arteriosclerosis via enhanced incorporation of bone marrow-derived endothelial progenitor cells," Arteriosclerosis, Thrombosis, and Vascular Biology, vol. 28, no. 2, pp. 278-283, 2008.

[205] R. Noor, U. Shuaib, C. X. Wang et al., "High-density lipoprotein cholesterol regulates endothelial progenitor cells by increasing eNOS and preventing apoptosis," Atherosclerosis, vol. 192, no. 1, pp. 92-99, 2007.

[206] G. Ferretti, T. Bacchetti, A. Nègre-Salvayre, R. Salvayre, N. Dousset, and G. Curatola, "Structural modifications of HDL and functional consequences," Atherosclerosis, vol. 184, no. 1, pp. $1-7,2006$.

[207] M. P. Reilly, F. C. McGillicuddy, M. L. De La Moya et al., "Inflammation impairs reverse cholesterol transport in vivo," Circulation, vol. 119, no. 8, pp. 1135-1145, 2009.

[208] B. Shao, C. Bergt, X. Fu et al., "Tyrosine 192 in apolipoprotein A-I is the major site of nitration and chlorination by myeloperoxidase, but only chlorination markedly impairs ABCA1-dependent cholesterol transport," Journal of Biological Chemistry, vol. 280, no. 7, pp. 5983-5993, 2005.

[209] C. Bergt, S. Pennathur, X. Fu et al., "The myeloperoxidase product hypochlorous acid oxidizes HDL in the human artery wall and impairs ABCA1-dependent cholesterol transport," Proceedings of the National Academy of Sciences of the United States of America, vol. 101, no. 35, pp. 13032-13037, 2004.

[210] S. Pennathur, C. Bergt, B. Shao et al., "Human atherosclerotic intima and blood of patients with established coronary artery disease contain high density lipoprotein damaged by reactive nitrogen species," Journal of Biological Chemistry, vol. 279, no. 41, pp. 42977-42983, 2004.

[211] J. W. Heinecke, F. F. Hsu, J. R. Crowley et al., "Detecting oxidative modification of biomolecules with isotope dilution mass spectrometry: sensitive and quantitative assays for oxidized amino acids in proteins and tissues," Methods in Enzymology, vol. 300, pp. 124-144, 1998.

[212] B. Shao and J. W. Heinecke, "Impact of HDL oxidation by the myeloperoxidase system on sterol efflux by the ABCA1 pathway," Journal of Proteomics, vol. 74, no. 11, pp. 2289-2299, 2011.

[213] D. Peng, Z. Wu, G. Brubaker et al., “Tyrosine modification is not required for myeloperoxidase-induced loss of apolipoprotein AI functional activities," Journal of Biological Chemistry, vol. 280, no. 40, pp. 33775-33784, 2005.

[214] B. Shao, M. N. Oda, C. Bergt et al., "Myeloperoxidase impairs ABCA1-dependent cholesterol efflux through methionine oxidation and site-specific tyrosine chlorination of apolipoprotein A-I," Journal of Biological Chemistry, vol. 281, no. 14, pp. 90019004, 2006.

[215] L. Zheng, M. Settle, G. Brubaker et al., "Localization of nitration and chlorination sites on apolipoprotein A-I catalysed by myeloperoxidase in human atheroma and associated oxidative impairment in ABCA1-dependent cholesterol efflux from macrophages," Journal of Biological Chemistry, vol. 280, no. 1, pp. $38-47,2005$.

[216] B. Shao, C. Tang, J. W. Heinecke, and J. F. Oram, "Oxidation of apolipoprotein A-I by myeloperoxidase impairs the initial interactions with $\mathrm{ABCA1}$ required for signaling and cholesterol export," Journal of Lipid Research, vol. 51, no. 7, pp. 1849-1858, 2010.

[217] C. Tang, Y. Liu, P. S. Kessler, A. M. Vaughan, and J. F. Oram, "The macrophage cholesterol exporter ABCA1 functions as an anti-inflammatory receptor," Journal of Biological Chemistry, vol. 284, no. 47, pp. 32336-32343, 2009. 
[218] B. Shao, S. Pennathur, I. Pagani et al., "Modifying apolipoprotein A-I by malondialdehyde, but not by an array of other reactive carbonyls, blocks cholesterol efflux by the ABCA1 pathway," Journal of Biological Chemistry, vol. 285, no. 24, pp. 18473-18484, 2010.

[219] A. Hoang, A. J. Murphy, M. T. Coughlan et al., "Advanced glycation of apolipoprotein A-I impairs its anti-atherogenic properties," Diabetologia, vol. 50, no. 8, pp. 1770-1779, 2007.

[220] M. Passarelli, C. Tang, T. O. McDonald et al., "Advanced glycation end product precursors impair ABCA1-dependent cholesterol removal from cells," Diabetes, vol. 54, no. 7, pp. 21982205, 2005.

[221] K. Isoda, E. J. Folco, K. Shimizu, and P. Libby, "AGE-BSA decreases ABCG1 expression and reduces macrophage cholesterol efflux to HDL," Atherosclerosis, vol. 192, no. 2, pp. 298-304, 2007.

[222] E. Nobécourt, J. Zeng, M. J. Davies et al., "Effects of cross-link breakers, glycation inhibitors and insulin sensitisers on HDL function and the non-enzymatic glycation of apolipoprotein AI," Diabetologia, vol. 51, no. 6, pp. 1008-1017, 2008.

[223] E. Nobecourt, F. Tabet, G. Lambert et al., "Nonenzymatic glycation impairs the antiinflammatory properties of apolipoprotein A-I," Arteriosclerosis, Thrombosis, and Vascular Biology, vol. 30, no. 4, pp. 766-772, 2010. 

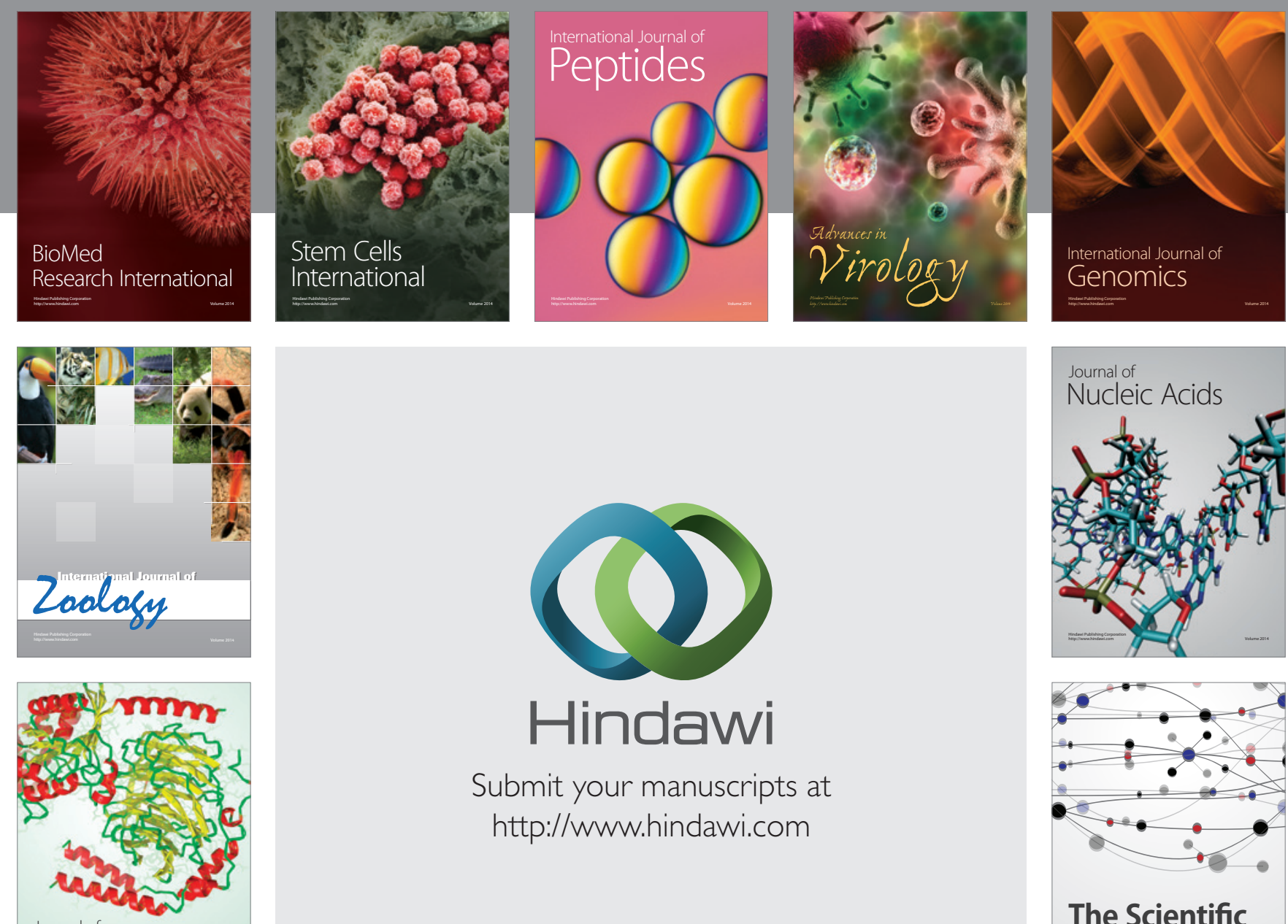

Submit your manuscripts at

http://www.hindawi.com

Journal of
Signal Transduction
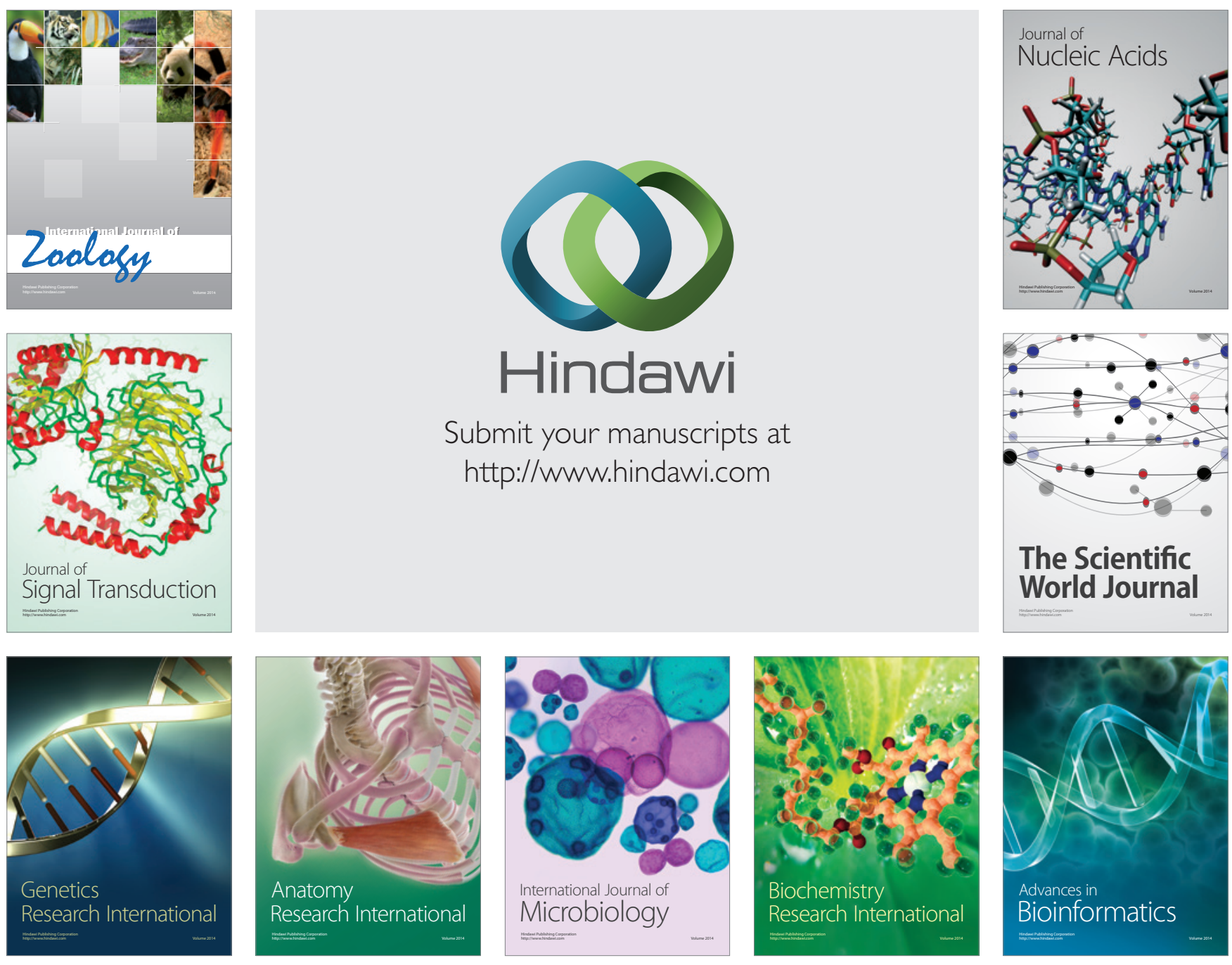

The Scientific World Journal
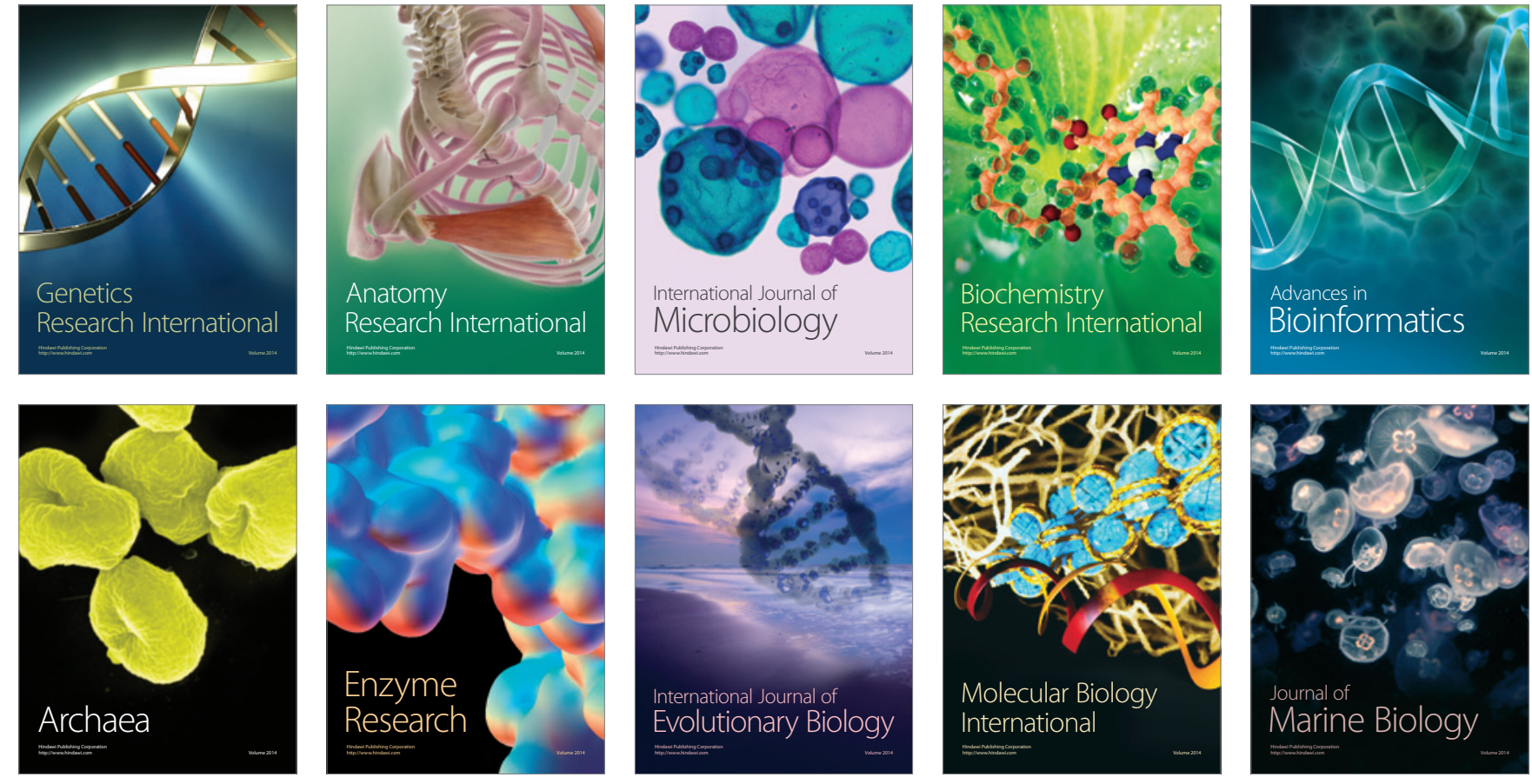